\title{
The Environmental and Macroeconomic Effects of Socially Responsible Investment
}

\author{
LAMMERTJAN DAM \\ BEN J. HEIJDRA
}

CESIFO WORKING PAPER NO. 2349

CATEgory 1: Public FinANCE

JULY 2008

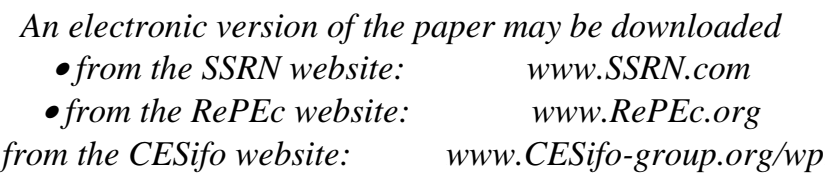




\title{
The Environmental and Macroeconomic Effects of Socially Responsible Investment
}

\begin{abstract}
We analyze the effects of socially responsible investment and public abatement on environmental quality and the economy in a continuous-time dynamic growth model featuring optimizing households and firms. Environmental quality is modelled as a renewable resource. Consumers can invest in government bonds or firm equity. Since investors feel partly responsible for environmental pollution when holding firm equity, they require a premium on the return to equity. We show that socially responsible investment behaviour by households partially offsets the positive effects on environmental quality of public abatement policies.

JEL Code: H23, M14, O16, O41, Q21.

Keywords: socially responsible investment, economic growth, environmental economics, resource dynamics, stock market.

Lammertjan Dam

Faculty of Economics and Business

University of Groningen

P.O. Box 800

9700 AV Groningen

The Netherlands

l.dam@rug.nl

Ben J. Heijdra

Faculty of Economics and Business

University of Groningen

P.O. Box 800

9700 AV Groningen

The Netherlands

info@heijdra.org
\end{abstract}

July 2008 


\section{Introduction}

Socially responsible investment is a portfolio management style that does not only rely on financial returns, but also on non-financial characteristics of the companies associated with the shares in the portfolio. The notion nowadays is that many investors do not only care about cash flows, but also about how these cash flows are generated. An investor might, for example, abstain from investing in firms that use child labor or adopt heavily polluting technologies. The modern investor thus distinguishes between "sin stocks" and clean investment opportunities (see, e.g., Hong and Kacperczyk 2005). In this context, Fama and French (2005) have recently acknowledged that there exists a "taste for assets", as if the assets themselves can be seen as consumption goods. The most common form of socially responsible investment used in practice is straightforward screening, i.e. stocks of companies that "misbehave"-according to some threshold measure-are simply eliminated from the portfolio. This style of investing has witnessed increasing attention and experienced large growth figures. There is ample anecdotal evidence to support this claim. In 2005, for example, about one out of every ten dollars under professional management in the United States was subject to some form of socially responsible screening (Social Investment Forum, 2006). Also, the April 2008 issue of the popular magazine Institutional Investor reports that U.S. investor groups have currently filed 54 resolutions on climate change, up from 43 resolutions just one year before. Many resolutions call on firms to disclose their greenhouse gas emissions.

Socially responsible investment (or "green screening") can serve as a tool in dealing with environmental externalities. In this paper, we analyze the macroeconomic and environmental effects of socially responsible portfolio investment behaviour in the presence of environmental pollution due to production. We are interested in how a traditional fiscal policy (such as a public abatement program) interacts with socially responsible investments. In particular, it is interesting to find out, first, whether these two types of policies are complements or substitutes for each other, and, second, whether socially responsible investment has an effect on the transitional effects triggered by fiscal policy. More precisely, we consider two shocks, namely, first, a change in the level of public abatement and, second, a change in the perceived pollution coefficient.

Our paper relates to the literature on "green consumerism" (Bansal and Gangopadhyay, 2003; Nyborg et al. (2006); Björner et al., 2004), and it is a natural choice to push the types of arguments made in that literature in the direction of "green investing". Indeed, one of the main contributions of this paper is to formulate a simple and tractable way to model socially responsible investment in a micro-founded dynamic macroeconomic model inhabited by optimizing agents.

There exists a huge body of empirical literature on socially responsible investing that is particularly interested in the relationship between corporate social and financial performance. Two widely cited survey articles on this topic are Margolis and Walsh (2001) and Orlitzky 
et al. (2003). In contrast, there are far fewer attempts to analyze the effects of socially responsible investing in a theoretical framework. Heinkel et al. (2001) study a static model with green screening in the portfolio selection (see also Beltratti, 2005). Their model is similar to the asymmetric information model by Merton (1987). Dam (2006a) studies socially responsible investment and corporate socially responsibility in a (static) general equilibrium stock market model, using insights from Diamond (1967). In a dynamic setting, Kriström and Lundgren (2003) present a partial equilibrium model in which profits are affected by "green goodwill". However, their model is not explicitly on socially responsible investment, since their approach implies that green goodwill is channeled through the consumer goods market. Dam (2006b) studies the role of socially responsible investment in a Diamond (1965)-type overlapping generations model to capture the conflict between current and future generations.

The remainder of the paper is structured as follows. In Section 2 we present the model. Households feature a "warm-glow" environmental preservation motive in the sense that they feel partially responsible for the pollution caused by firms in which they hold shares. In order to induce the household-investor to hold shares, these "dirty" securities must yield a higher rate of return than "clean" government bonds. From the point of view of the representative firm, the warm-glow motive of investors acts as an implicit output tax. Through this channel, therefore, socially responsible investment affects the firm's output and capital accumulation decisions. In Section 3, we loglinearize the model and prove existence and saddle-point stability of the macroeconomic equilibrium. In Section 4 we use the loglinearized model to conduct comparative dynamic experiments. The first shock consists of an (unanticipated and permanent) increase in the level of public abatement. Interestingly, this shock weakens (and partially crowds out) the warm-glow motive of socially responsible investors. In the second experiment we study the effects of a permanent increase in the warm-glow parameter, i.e., a strengthening of investors' social responsibility. Finally, in Section 5 we offer some conclusions and possible extensions.

\section{The model}

\section{$2.1 \quad$ Households}

There exists a large (and fixed) number, $H$, of identical, infinitely lived households. From the perspective of the planning period, $t$, the representative household possesses a lifetime utility function of the following form:

$$
\Lambda(t) \equiv \int_{t}^{\infty} U[c(\tau), p(\tau), Q(\tau)] e^{\rho(t-\tau)} d \tau
$$

where $c$ is consumption, $p$ is an index of the flow of pollution caused by firms that the household holds shares in, $Q$ is the stock of environmental quality, and $\rho$ is the pure rate of time preference. Consumers do not fully internalize the environmental externality, however, 
they do experience a "warm glow" from contributing to the public good, as in Andreoni (1990). ${ }^{1}$ In equation (1), $Q$ represents the external effect on utility whilst $p$ denotes the warm-glow effect. The warm glow is channeled through socially responsible investment-see below.

To keep the model as simple as possible, we assume that the felicity function, $U[\cdot]$, is log-linear in its arguments: ${ }^{2}$

$$
U[c, p, Q] \equiv \ln c-\beta \ln (1+p)+\zeta \ln Q, \quad \beta>0, \quad \zeta>0 .
$$

This specification of preferences implies that the intertemporal substitution elasticity for private consumption is equal to unity. Furthermore, the felicity function is separable in its arguments, a features which simplifies the analysis considerably.

We model social responsibility by assuming that the household feels responsible for a proportion of the "dirt" produced by the firms in which it holds shares. We assume that there are two types of financial claims in the economy, namely "clean" government bonds and "dirty" firm equity. ${ }^{3}$ The household feels responsible for the share-weighted relative pollution levels (as in Dam, 2006a, 2006b):

$$
p=\frac{e}{\bar{E}} \cdot \frac{\gamma Y}{Q}, \quad \gamma>0,
$$

where $Y$ and $\bar{E}$ are, respectively, aggregate output and the total number of outstanding firm shares. Furthermore, $e$ is the number of shares the household possesses, so $e / \bar{E}$ is the fraction of firms owned by the invidual household. Finally, $\gamma$ is a constant parameter capturing the notion that production generates undesirable side effects, e.g. pollution. The stock of environmental quality, $Q$, features in the denominator, i.e. it is the $Y / Q$ ratio that affects the agent. In its decision making, the household takes as given the paths for $Y$ and $Q$. By assumption, the total number of shares of companies $(\bar{E})$ is fixed, so the household can only influence $p$ by choosing its share holdings, $e$.

The household can save by investing in shares or in government bonds (to keep matters simple, there are no corporate bonds ${ }^{4}$ ). In this deterministic setting, there is no risk so bonds and shares are perfect substitutes in the household's portfolio. The household budget identity is thus given by:

$$
\dot{b}+P_{e} \dot{e}+c=W+d+r b-z,
$$

\footnotetext{
${ }^{1}$ Nyborg et al. (2006) provide a detailed discussion of the psychological motivation for this kind of behaviour in the context of green consumption.

${ }^{2}$ We drop the time index, where no confusion can arise.

${ }^{3}$ Households assume that the government engages in clean activities, i.e. it screens out all socially irresponsible activities. The assumption of a single dirty asset simplifies the analysis without significant loss of generality. The model can be easily generalized by recognizing heterogeneous firms differing in their $\gamma$-parameters. In such a setting, the dirtier firms will have a higher rate of return. See also below.

${ }^{4}$ If there were corporate bonds, we postulate that investors would treat them as dirty assets, i.e. as equivalent to equity. Under this assumption, ignoring corporate bonds entails no loss of generality.
} 
where $b$ denotes government bonds, $P_{e}$ is the stock market price of company shares, $W$ is the wage rate, $d$ is dividends received from firms, $r$ is the interest rate, and $z$ is lump-sum taxes paid to the government. Labour supply is exogenous and equal to unity, so $W$ also stands for the household's wage income. As usual, a variable with a dot is that variable's time rate of change, e.g. $\dot{b} \equiv d b(\tau) / d \tau$. In the planning period, $t$, the household faces the initial conditions $e(t)=e_{0} \equiv \bar{E} / H$ and $b(t)=b_{0} \cdot{ }^{5}$ The dividend payout ratio, $\pi$, is defined as follows:

$$
\pi \equiv \frac{D}{P_{e} \bar{E}}
$$

where $D$ stands for total dividend payments by firms. The dividend payout ratio is determined by the firm and taken parametrically by the household, i.e. dividend receipts of the individual investor amount to $d=\pi P_{e} e$.

The household chooses time paths for $c, b, e$ in order to maximize (1) subject to (4), taking into account (2)-(5), and some transversality conditions. The household optimization program constitutes a non-standard optimal control problem which can, however, be solved by transforming it. We demonstrate in Appendix A that the key expressions characterizing individual household behaviour in an interior optimum (with all assets held in positive amounts) are given by:

$$
\begin{aligned}
\frac{\dot{c}}{c} & =r-\rho, \\
r_{e}-r & =\beta \cdot \frac{c}{1+p} \cdot \frac{\gamma}{Q} \cdot \frac{Y}{P_{e} \bar{E}}, \\
a & =b+P_{e} e,
\end{aligned}
$$

where $r_{e} \equiv \dot{P}_{e} / P_{e}+\pi$ is the pecuniary rate of return on shares. Equation (6) is the conventional Euler equation, equating the growth rate in consumption to the gap between the interest rate and the pure rate of time preference. Equation (7) is the no-arbitrage equation for shares and bonds. Intuitively, since $\beta$ is positive, the individual investor demands a higher rate of return on shares than on clean bonds $\left(r_{e}>r\right)$, because the former give rise to undesirable side effects in the form of pollution. Ceteris paribus, the excess return depends positively on $\gamma$ and negatively on $Q$ and the equity value per unit of output, $v \equiv P_{e} \bar{E} / Y{ }^{6}$ Finally, equation (8) shows that total financial wealth consists of bonds plus the market value of shares.

Since agents are identical, aggregate values pertaining to the household sector are defined in a straightforward fashion, i.e. $C \equiv H c, A \equiv H a, B \equiv H b, Z \equiv H z$. Each agent

\footnotetext{
${ }^{5}$ To keep the model symmetric, and thus to be able to employ the notion of a representative agent, we assume that in the initial equilibrium each household has an endowment of shares equal to $\bar{E} / H$. In the optimum there will be no net trades in shares, i.e. $e(t)=\bar{E} / H$ for all $t$. As a result, optimal investment behaviour will give rise to an equilibrium price of shares.

${ }^{6}$ Of course, for $\beta=0$ the agent does not feel a warm glow effect and thus does not demand an excess return on shares, i.e. $r_{e}=r$ in that case.
} 
holds the same amount of shares, $e=\bar{E} / H$, and experiences the same warm glow effect, $p=\gamma Y /(H Q)$. Aggregate assets satisfy $A=B+K$. The household sector is summarized in Table 1 by equations (T1.1) and (T1.5).

Table 1: Main Model Equations

$$
\begin{aligned}
\frac{\dot{C}}{C} & =r-\rho \\
\dot{K} & =Y-C-G-\delta K \\
W & =(1-\theta) F_{L}[K, H] \\
r+\delta & =(1-\theta) F_{K}[K, H] \\
Y & =F[K, H] \\
\theta & =\frac{\beta \gamma C}{H Q+\gamma Y} \\
z H & =r B+G \\
\dot{Q} & =\mu \cdot(-Q+\phi+\xi G-\eta Y)
\end{aligned}
$$

Notes: $C$ is consumption, $r$ is the interest rate, $\rho$ is the rate of time preference, $K$ is the capital stock, $H$ is labour supply, $G$ is public abatement, $\delta$ is the depreciation rate of capital, $\theta$ is the implicit tax (warm glow), $Q$ is environmental quality, $Y$ is output, $z$ is the lump-sum tax per agent, $B$ is the stock of government bonds. Parameters $\beta, \gamma, \mu, \xi$, and $\eta$ are all positive.

\section{$2.2 \quad$ Firms}

There are many, perfectly competitive firms, using a constant returns to scale technology to produce a single homogeneous good. We argue on the basis of the representative firm. To keep the model as simple as possible, we abstract from corporate debt (so that financing is by retained earnings only).

Gross operating profit of the firm is denoted by $\Pi$ and defined as:

$$
\Pi \equiv F[K, L]-W L,
$$

where $K$ is the physical capital stock, $L$ is labour demand, and $F[K, L] \equiv K^{\alpha} L^{1-\alpha}$ is a CobbDouglas (constant returns to scale) production function. Corporate profit is either paid out to household-investors in the form of dividends, $D$, or kept in the form of retained earnings, $R E$ :

$$
\Pi=D+R E .
$$


The capital accumulation identity is given by:

$$
\dot{K}=I-\delta K
$$

where $I$ is gross investment, $\delta$ is the depreciation rate, and $\dot{K}(\tau) \equiv d K / d \tau$ is net investment.

The no-arbitrage equation for household-investors, equation (7), can be written as:

$$
r=\frac{\dot{P}_{e}}{P_{e}}+\frac{D-\theta Y}{P_{e} \bar{E}}
$$

where $\theta$ can be seen as an "implicit tax" that the firm faces as a result of the investors' warm glow motive:

$$
\theta \equiv \frac{\beta \gamma c}{(1+p) Q}
$$

We assume that parameters are such that $\theta$ is positive but less than one $(0<\theta<1)$. In equation (12), $\theta Y$ can be interpreted as a negative dividend (undesirable pollution) resulting from the firm's production activities.

We show in Appendix B that the objective function of the firm is given by:

$$
V(t)=\int_{t}^{\infty}[[1-\theta(\tau)] F[K(\tau), L(\tau)]-W(\tau) L(\tau)-I(\tau)] e^{R(t, \tau)} d \tau,
$$

where $R(t, \tau) \equiv \exp \left[-\int_{t}^{\tau} r(s) d s\right]$ is the interest factor. The firm chooses optimal time paths for $K, I$, and $L$ in order to maximize (14), subject to the accumulation identity (11), the path of implicit taxes, and taking as given the initial capital stock, $K(t)$. The key first-order necessary conditions for an interior solution can be written as follows:

$$
\begin{aligned}
W & =(1-\theta) F_{L}[K, L], \\
r+\delta & =(1-\theta) F_{K}[K, L],
\end{aligned}
$$

and it follows that $V(t)=K(t)$. Equations (15)-(16) are the standard rental expressions for labour and capital.

\section{Model summary}

The key expressions of the model are collected in Table 1. Equation (T1.1) is the aggregate consumption Euler equation. Equation (T1.2) is the macroeconomic capital accumulation expression, showing that the net change in the capital stock, $\dot{K}$, equals net output, $Y-\delta K$, minus the sum of private consumption and public abatement, $C+G$. Equations (T1.3)-(T1.4) just restate the factor rental expressions (15)-(16), with labour market clearing, $L=H$, imposed. Equation (T1.5) is the aggregate production function. Equation (T1.6) expresses the implicit tax faced by firms, $\theta$, in terms of macro variables, $C, Y$, and $Q$. It is obtained by rewriting the no-arbitrage equation (7) somewhat. It is easy to verify that $\partial \theta / \partial Q<0$, 
$\partial \theta / \partial Y<0, \partial \theta / \partial C>0$, and $\partial \theta / \partial \gamma>0$. Equation (T1.7) is the static government budget constraint, showing that the lump-sum tax revenue (left-hand side) equals total government spending, consisting of interest payments on existing government debt plus abatement expenditure (right-hand side). Below we assume $B$ to be fixed, and consider $G$ to be an exogenous policy variable under government control. Throughout the paper, the lump-sum tax is assumed to balance the budget. Finally, equation (T1.8) show the dynamic expression for the stock of environmental quality. Following John and Pecchenino (1994) and Bovenberg and Heijdra (1998), we assume that nature features a regenerative capacity and, for given values of $Y$ and $G$, slowly settles into a steady-state quality level, $\hat{Q}=\phi+\xi G-\eta \hat{Y}$, where hats denote steady-state values. We assume that $\hat{Q}$ is positive. The parameter $\mu$ measures the speed of regeneration, which we take to be finite in the general case. Occasionally, however, we shall consider the special case of $\mu \rightarrow \infty$, in which case adjustment in environmental quality is instantaneous, i.e. $Q$ has the flow dimension. To summarize, the endogenous variables of the model are $C, Y, K, Q, W, r, \theta$, and $z$. The exogenous variables are $H, B$, and $G$.

In order to further investigate the model properties and to prepare for the comparative dynamic analyses conducted in the next section, we log-linearize the model around an initial steady state-see Table 2 . The definitions of the variables and shares parameters are also stated at the bottom of Table 2. The stability analysis depends on the speed of adjustment of nature, $\mu$.

Table 2: Log-linearized Model

$$
\begin{aligned}
\dot{\tilde{C}} & =\rho \tilde{r} \\
\dot{\tilde{K}} & =\hat{y} \cdot\left[\tilde{Y}-\omega_{C} \tilde{C}-\omega_{G} \tilde{G}-\omega_{I} \tilde{K}\right] \\
\tilde{W} & =\alpha \tilde{K}-\frac{\hat{\theta}}{1-\hat{\theta}} \tilde{\theta} \\
\frac{\rho}{\rho+\delta} \tilde{r} & =-(1-\alpha) \tilde{K}-\frac{\hat{\theta}}{1-\hat{\theta}} \tilde{\theta} \\
\tilde{Y} & =\alpha \tilde{K} \\
\tilde{\theta} & =\tilde{C}-\left(1-\omega_{Q}\right) \tilde{Y}-\omega_{Q} \tilde{Q}+\omega_{Q} \tilde{\gamma} \\
\tilde{Z} & =\omega_{B} \tilde{r}+\omega_{G} \tilde{G} \\
\dot{\tilde{Q}} & =\mu \cdot\left[-\tilde{Q}+\varepsilon_{G} \tilde{G}-\varepsilon_{Y} \tilde{Y}\right]
\end{aligned}
$$

Notes. (i) Variables are defined as follows: $\dot{\tilde{x}}(t) \equiv d \dot{x}(t) / \hat{x}$ and $\tilde{x}(t) \equiv d x(t) / \hat{x}$. Exception: $\tilde{Z} \equiv H d z / \hat{Y}$. (ii) Steady-state shares are defined as: $\omega_{C} \equiv \hat{C} / \hat{Y}, \omega_{G} \equiv G / \hat{Y}, \hat{y} \equiv \hat{Y} / \hat{K}, \omega_{B} \equiv$ $\rho B / \hat{Y}, \omega_{Q} \equiv H \hat{Q} /[H \hat{Q}+\gamma \hat{Y}], \varepsilon_{G} \equiv \xi G / \hat{Q}, \varepsilon_{Y} \equiv \eta \hat{Y} / \hat{Q}$. (iii) Relationship between shares: $\omega_{I}=$ $\delta / \hat{y}=1-\omega_{C}-\omega_{G}, \rho+\delta=\alpha(1-\hat{\theta}) \hat{y}, \hat{\theta}=\beta \omega_{C}\left(1-\omega_{Q}\right), \alpha-\omega_{I}=(\rho+\delta \hat{\theta}) /[(1-\hat{\theta}) \hat{y}]>0$. 
$\mathrm{Q}$ as a flow Under the flow interpretation, we set $\mu \rightarrow \infty$ and find that the quality of nature, $Q$, adjusts immediately. The dynamical system for consumption and the capital stock can be written in a simple matrix expressions as:

$$
\left[\begin{array}{c}
\dot{\tilde{C}} \\
\dot{\tilde{K}}
\end{array}\right]=\Delta \cdot\left[\begin{array}{c}
\tilde{C} \\
\tilde{K}
\end{array}\right]+\Gamma
$$

where the Jacobian matrix, $\Delta$, possessing typical elements $\delta_{i j}$, is defined as:

$$
\Delta \equiv\left[\begin{array}{cc}
-\alpha \hat{y} \hat{\theta} & -\alpha \hat{y}\left[(1-\alpha)(1-\hat{\theta})-\alpha \hat{\theta}\left[1-\omega_{Q}\left(1+\varepsilon_{Y}\right)\right]\right] \\
-\hat{y} \omega_{C} & \hat{y}\left(\alpha-\omega_{I}\right)
\end{array}\right]
$$

and the shock vector is given by:

$$
\Gamma \equiv\left[\begin{array}{l}
-\alpha \hat{y} \hat{\theta} \omega_{Q}\left[\tilde{\gamma}-\varepsilon_{G} \tilde{G}\right] \\
-\hat{y} \omega_{G} \tilde{G}
\end{array}\right]
$$

The stability analysis proceeds as follows. It is easy to show that the trace of $\Delta$ is positive:

$$
\operatorname{tr} \Delta=\hat{y}\left[(1-\hat{\theta}) \alpha-\omega_{I}\right]=\rho>0
$$

suggesting that there is at least one positive characteristic root. The determinant of $\Delta$ is equal to:

$$
|\Delta|=-\alpha \hat{y}^{2}\left[\hat{\theta}\left(\alpha-\omega_{I}\right)+\omega_{C}\left(1-\alpha-\hat{\theta}+\alpha \hat{\theta} \omega_{Q}\left(1+\varepsilon_{Y}\right)\right)\right] .
$$

In the absence of the warm-glow effect $(\hat{\theta}=0)$, the determinant is negative and the model is saddle-point stable, i.e. it possesses one positive (unstable) root, say $\lambda_{1}>0$, and one negative (stable) root, say $-\lambda_{2}<0$. The roots satisfy the usual relationships, i.e. $\lambda_{1}=\rho+\lambda_{2}$ and $|\Delta|=-\lambda_{1} \lambda_{2}$. With an operative warm-glow effect the implicit tax is positive, and saddlepoint stability is not guaranteed for all parameter values. Since $\alpha>\omega_{I}$, however, a very mild sufficient condition for saddle-point stability is that $\alpha+\hat{\theta}<1$, which we assume from here on. ${ }^{7}$ To summarize, the model is saddle-point stable, with consumption and the capital stock acting as, respectively, the non-predetermined ("jumping") variable and the predetermined ("sticky") variable.

$\mathrm{Q}$ as a stock Under the stock interpretation, $\mu$ is finite and the quality of nature only changes gradually over time. As a result, there are now three dynamic variables, namely $C$,

\footnotetext{
${ }^{7}$ Recall that $\alpha$ represents the capital share of national income, for which $a=1 / 3$ is a plausible value. The implicit tax, though positive, is likely to be quite small, easily satisfying the sufficient condition.
} 
$K$, and $Q$. Saddle-point stability now requires there to be two stable roots, and one unstable root. The matrix expression for the dynamical system is given by:

$$
\left[\begin{array}{c}
\dot{\tilde{C}} \\
\dot{\tilde{K}} \\
\dot{\tilde{Q}}
\end{array}\right]=\bar{\Delta} \cdot\left[\begin{array}{c}
\tilde{C} \\
\tilde{K} \\
\tilde{Q}
\end{array}\right]+\bar{\Gamma}
$$

where $\bar{\Delta}$ and $\bar{\Gamma}$ are defined as follows:

$$
\begin{aligned}
\bar{\Delta} & \equiv\left[\begin{array}{ccc}
-\alpha \hat{y} \hat{\theta} & -\alpha \hat{y}\left[(1-\alpha)(1-\hat{\theta})-\alpha \hat{\theta}\left(1-\omega_{Q}\right)\right] & \alpha \hat{y} \hat{\theta} \omega_{Q} \\
-\hat{y} \omega_{C} & \hat{y}\left(\alpha-\omega_{I}\right) & 0 \\
0 & -\alpha \mu \varepsilon_{Y} & -\mu
\end{array}\right], \\
\bar{\Gamma} & \equiv\left[\begin{array}{l}
-\alpha \hat{y} \hat{\theta} \omega_{Q} \tilde{\gamma} \\
-\hat{y} \omega_{G} \tilde{G} \\
\mu \varepsilon_{G} \tilde{G}
\end{array}\right] .
\end{aligned}
$$

We find that $\operatorname{tr} \bar{\Delta}=\rho-\mu$ and $|\bar{\Delta}|=-\mu \cdot|\Delta|>0$, where we have used the fact that $|\Delta|<0$. We conclude that the model is saddle-point stable and write the characteristic roots as $\bar{\lambda}_{1}>0$, $-\bar{\lambda}_{2}<0$, and $-\bar{\lambda}_{3}<0 .{ }^{8}$

\section{Comparative Dynamics}

In this section we use the loglinearized model of Table 2 to investigate the impact, transitional, and long-run effects of two environmental shocks. In the first subsection we study a tax-financed increase in the level of public abatement, whilst in the second subsection we demonstrate what happens if there is an once-off increase in the warm-glow parameter, $\gamma$. For both shocks, we show the effects under both the flow and the stock interpretation of environmental quality.

\subsection{Public abatement}

Starting from an initial steady-state equilibrium, the economy is perturbed by an unanticipated and permanent increase in the level of public abatement. The government uses the lump-sum tax to balance its budget.

\subsubsection{Flow interpretation}

Under the flow interpretation of environmental quality, there are only two state variables and a convenient graphical representation of the model is available. Indeed, by using equations

\footnotetext{
${ }^{8}$ The Routh-Hurwitz condition ensures that the alternative case, with three positive characteristic roots, is impossible in our model.
} 


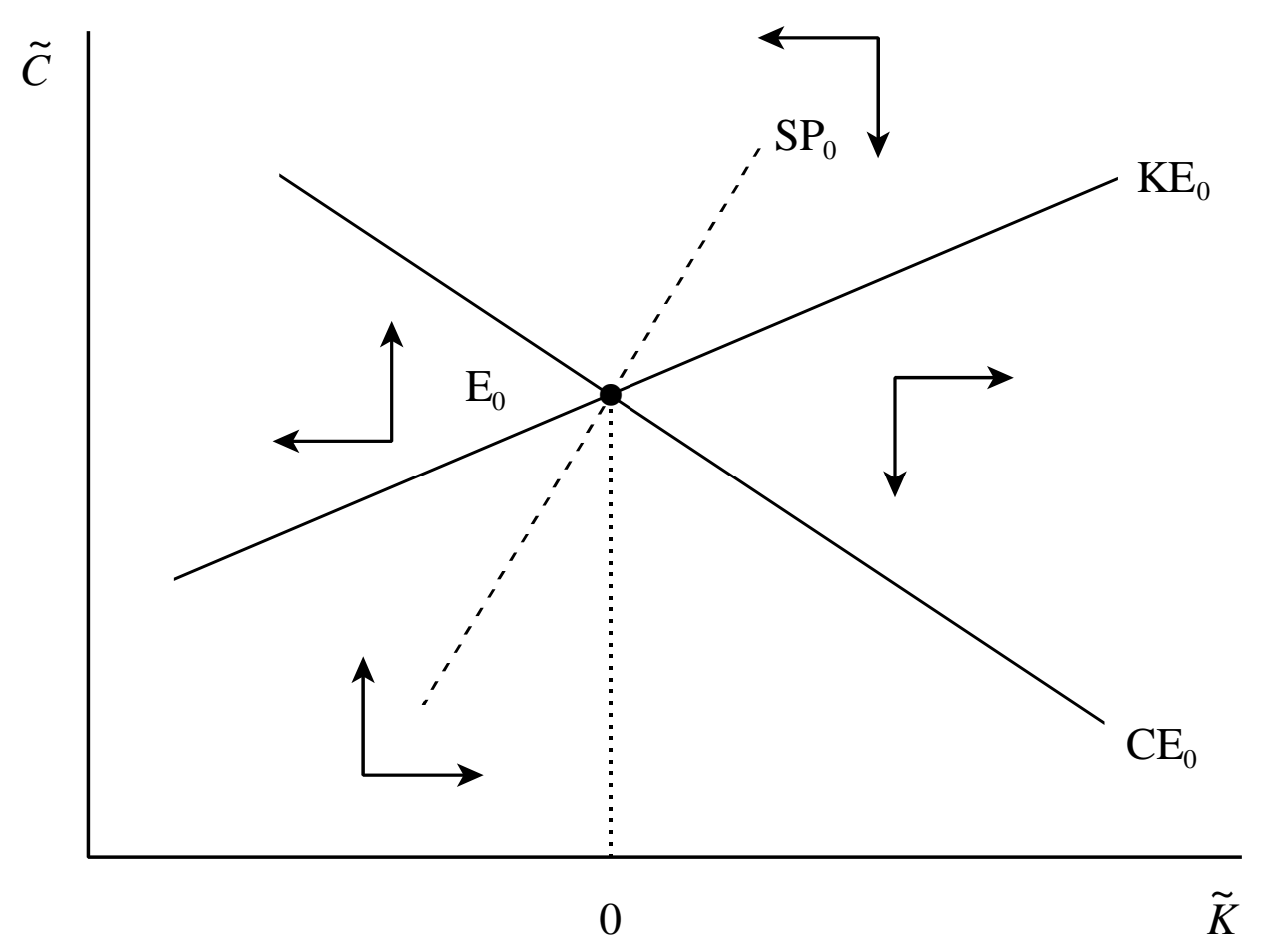

Figure 1: Phase Diagram

(17)-(19) and setting $\tilde{G}>0$ and $\tilde{\gamma}=0$ we find two equilibrium loci:

$$
\begin{aligned}
\tilde{C} & =-\frac{\delta_{12}}{\delta_{11}} \tilde{K}+\varepsilon_{G} \omega_{Q} \tilde{G}, \\
\tilde{C} & =-\frac{\delta_{22}}{\delta_{21}} \tilde{K}-\frac{\omega_{G}}{\alpha-\omega_{I}} \tilde{G},
\end{aligned}
$$

where $\delta_{i j}$ are the typical elements of $\Delta$ (given in (18) above) and we recall that $\delta_{11}<0$, $\delta_{12}<0, \delta_{21}<0, \delta_{22}>0, \alpha>\omega_{I}$, and $|\Delta| \equiv \delta_{11} \delta_{22}-\delta_{12} \delta_{21}<0$. Equation (25) depicts combinations for $\tilde{C}$ and $\tilde{K}$, for which $\dot{\tilde{C}}=0$. This is the consumption equilibrium line, $\mathrm{CE}_{0}$, in Figure 1. This line is downward sloping, and points to the right (left) of the line are consistent with a falling (rising) consumption profile, i.e. $\dot{\tilde{C}}<0(>0)$-see the vertical arrows in Figure 1.

Equation (26) gives combinations of $\tilde{C}$ and $\tilde{K}$, for which $\dot{\tilde{K}}=0$. This is the capital stock equilibrium line, $\mathrm{KE}_{0}$, in Figure 1. This line is upward sloping, and points above (below) the line are consistent with a falling (rising) capital stock, i.e. $\dot{\tilde{K}}<0(>0)$-see the horizontal arrows in Figure 1. The configuration of arrows confirms saddle-point stability: the initial equilibrium is at $\mathrm{E}_{0}$ and the saddle path is denoted by $\mathrm{SP}_{0}$.

An increase in public abatement shifts both curves in Figure 2. First, the CE curve shifts to the right from $\mathrm{CE}_{0}$ to $\mathrm{CE}_{1}$. Intuitively, following the abatement shock consumption equilibrium $(\hat{r}=\rho)$ is attained at a higher level of the capital stock and a lower implicit 


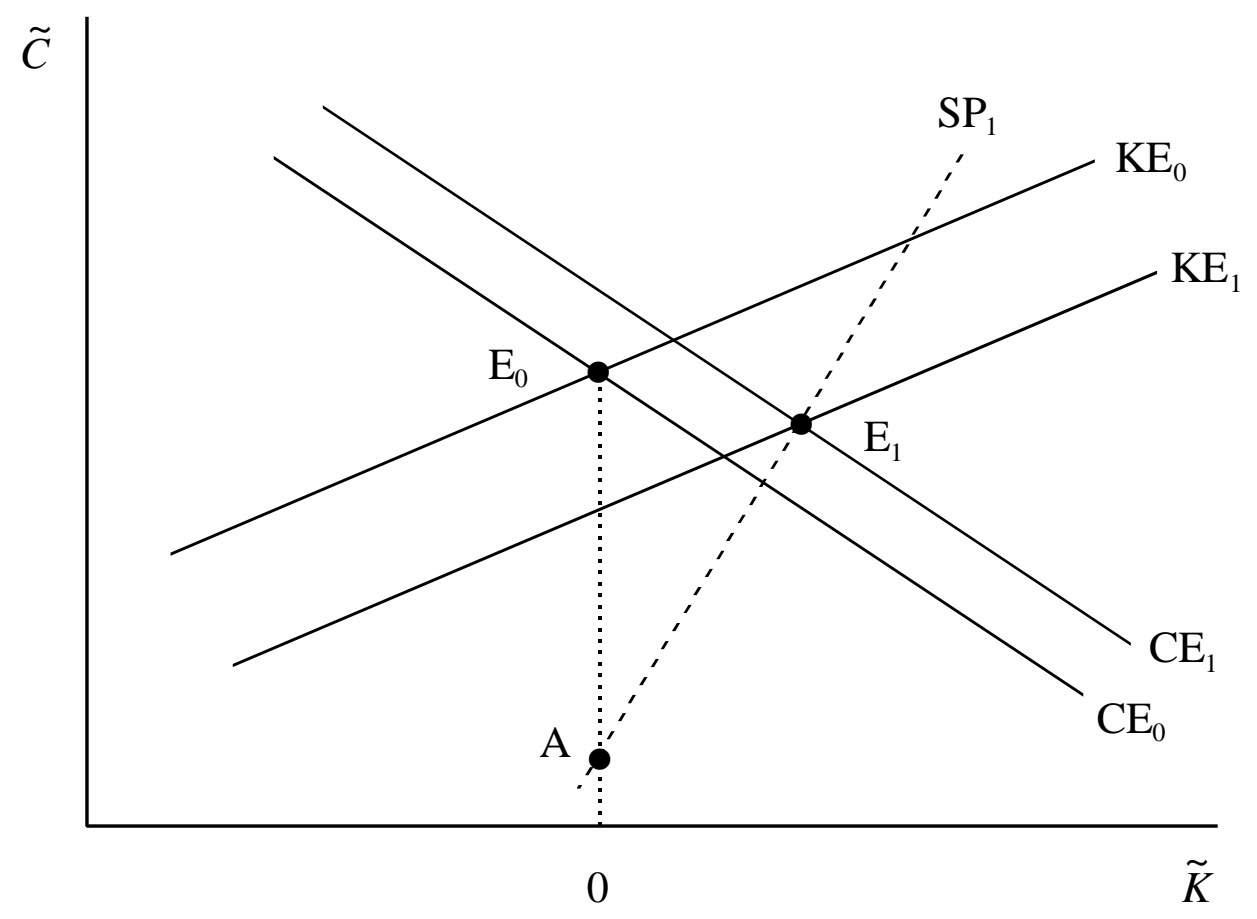

Figure 2: Increase in Public Abatement

tax, $\hat{\theta} .{ }^{9}$ Second, the abatement shock reduces the amount of resources available for private consumption and capital accumulation, thus shifting the $\mathrm{KE}$ line down, say from $\mathrm{KE}_{0}$ to $\mathrm{KE}_{1}$ in Figure 2. In the long run, the equilibrium shifts from $E_{0}$ to $E_{1}$, consumption decreases and the capital stock increases. The effect on environmental quality is ambiguous, because the capital stock (and thus output) increases the flow of pollution which may dominate the abatement effect.

At impact, the capital stock is predetermined and consumption falls as a result of the tax increase. This is the move from $\mathrm{E}_{0}$ to $\mathrm{A}$ on the new saddle path, $\mathrm{SP}_{1}$. At point $\mathrm{A}$, the interest rate exceeds the rate of time preference because the increase in public abatement decreases the implicit warm-glow tax. This means that consumption follows an upward sloping time profile during transition. At the same time, the reduction in consumption more than compensates for the increase in public abatement, thus resulting in net capital accumulation. During transition, the economy proceeds along the saddle path from point A to the new equilibrium at $\mathrm{E}_{1}$.

\footnotetext{
${ }^{9}$ Recall that $\hat{r}=\rho$ implies that $\rho+\delta=\alpha(1-\theta)(H / \hat{K})^{1-\alpha}$, from which the result mentioned in the text follows readily.
} 


\subsubsection{Stock interpretation}

Under the stock interpretation, the long-run effects are exactly the same as under the flow interpretation. There are, however, nontrivial differences in the adjustment paths toward the new equilibrium. Appendix $\mathrm{C}$ contains analytical expressions for the transition paths. In order to visualise the transition paths for the different variables, we calibrate the model using plausible parameter values. To keep things simple, we assume that the production function is of the Cobb-Douglas form, i.e. $Y=\Omega K^{\alpha} H^{1-\alpha}$. We set the scaling parameter equal to $\Omega=0.808$, normalize the number of households to unity, $H=1$, and set the capital share in national income at $\alpha=0.3$. The pure rate of time preference is set at 4 percent per annum, $\rho=0.04$, and annual capital depreciation is equal to $\delta=0.1$. The rate of natural regeneration is equal to $\mu=0.05$, and the remaining parameters of the ecological equation (T1.8) are chosen such that plausible values for the elasticitities $\varepsilon_{G}$ and $\varepsilon_{Y}$ are obtained. We find that $\phi=12.605$ and $\xi=\eta=6.464$. Finally, we set $\beta=0.5, \gamma=1$ and assume that the initial share of abatement equals $\omega_{G}=0.05$. Using these values in Table 1 , and solving for the steady state yields: $\hat{\theta}=0.05, \hat{Y}=1, \hat{r}=0.04, \hat{C}=0.746, \hat{K}=2.036$, and $\hat{Q}=6.464$, where hats denote steady-state values. At this steady state, the environmental elasticities are equal to $\varepsilon_{G}=0.05$ and $\varepsilon_{Y}=1$, and $\omega_{Q}=0.866$. The characteristic roots are real: $\lambda_{1}=0.212$, $-\lambda_{2}=-0.171$, and $-\lambda_{3}=-0.051$.

Figure 3 illustrates the adjustment paths for consumption, the capital stock, environmental quality, and the warm-glow tax following a ten percent increase in public abatement, from $G_{0}=0.05$ to $G_{1}=0.055$. All paths are monotonic and qualitatively the same as under the flow interpretation. The warm-glow tax falls at impact because of the downward jump in consumption. It continues to fall during transition because both output and environmental quality increase. 
$\tilde{C}(t)$

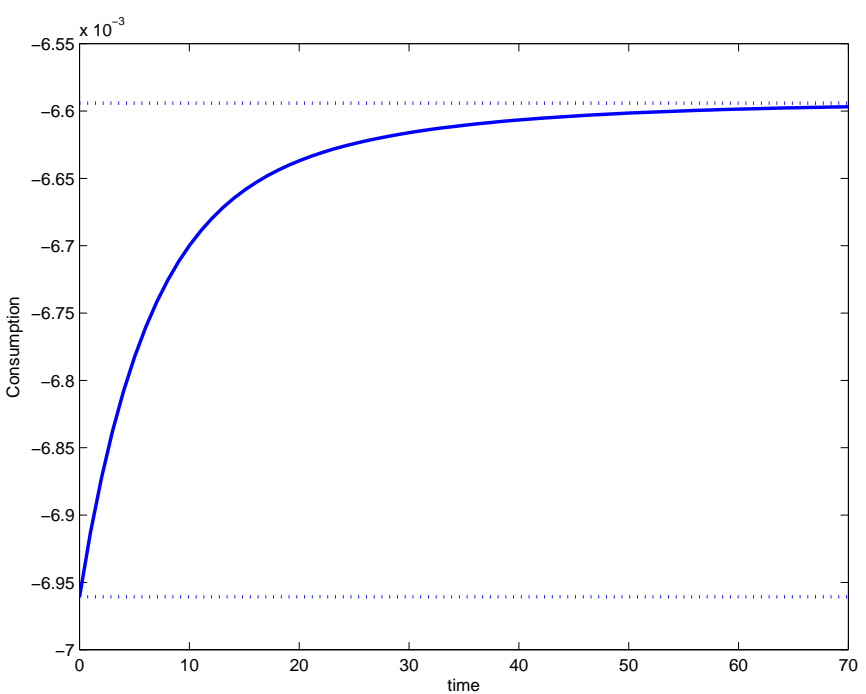

$\tilde{Q}(t)$

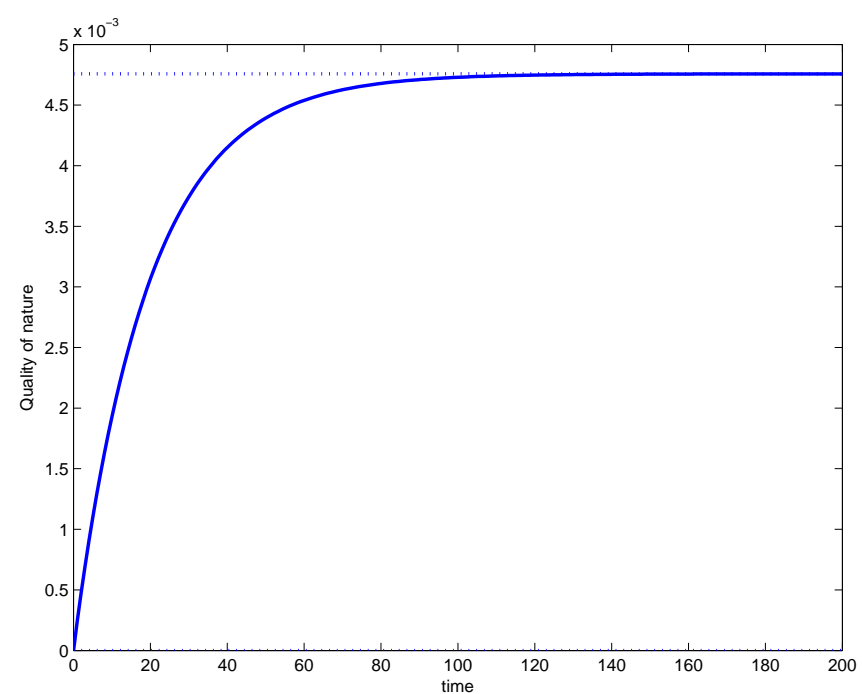

$\tilde{K}(t)$

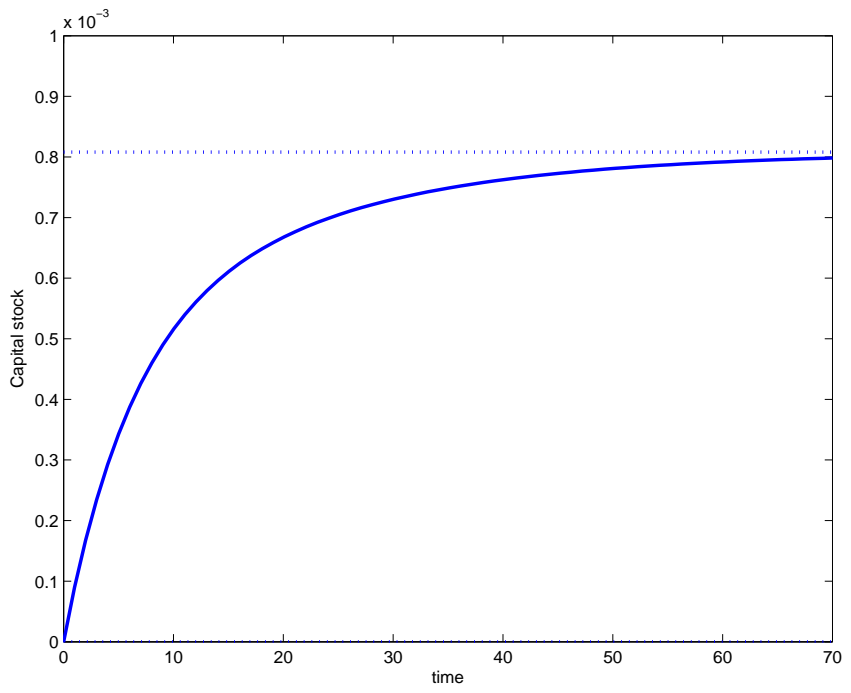

$\tilde{\theta}(t)$



Figure 3: Transition Path for the Abatement Shock (increase in $G$ ) 


\subsection{Stronger warm-glow effect}

In this subsection we study the effects of a stepwise increase in the warm-glow parameter, $\gamma$.

\subsubsection{Flow interpretation}

Under the flow interpretation, the $\mathrm{CE}$ and $\mathrm{KE}$ lines are given by, respectively,

$$
\tilde{C}=-\frac{\delta_{12}}{\delta_{11}} \tilde{K}-\omega_{Q} \tilde{\gamma},
$$

and:

$$
\tilde{C}=-\frac{\delta_{22}}{\delta_{21}} \tilde{K} .
$$

An increase in $\gamma$ shifts the $\mathrm{CE}$ curve down, say from $\mathrm{CE}_{0}$ to $\mathrm{CE}_{1}$ in Figure 4 . The $\mathrm{KE}$ line is unaffected because the shock does not affect resources available for private consumption and investment and for public abatement. At impact, the increase in $\gamma$ gives rise to an upward jump in consumption - the economy moves from $\mathrm{E}_{0}$ to point $\mathrm{A}$ on the new saddle path. At point $\mathrm{A}$, the interest rate exceeds the rate of time preference thus causing a downward sloping time profile for consumption along the saddle path. Intuitively, the shock leads to an increase in the warm-glow tax, both because $\gamma$ rises (direct effect) and because consumption increases (indirect effect). Point A lies above the KE line, which implies that capital decumulation takes place during transition. In the long run, both consumption and the capital are reduced, and the environmental quality is increased.

\subsubsection{Stock interpretation}

In Figure 5 we illustrate the adjustment paths for the key variables following a ten percent increase in the warm-glow parameter, from $\gamma_{0}=1$ to $\gamma_{1}=1.1$. The paths for consumption, the capital stock, the warm-glow tax, and environmental quality are all monotonic, as under the flow interpretation. 


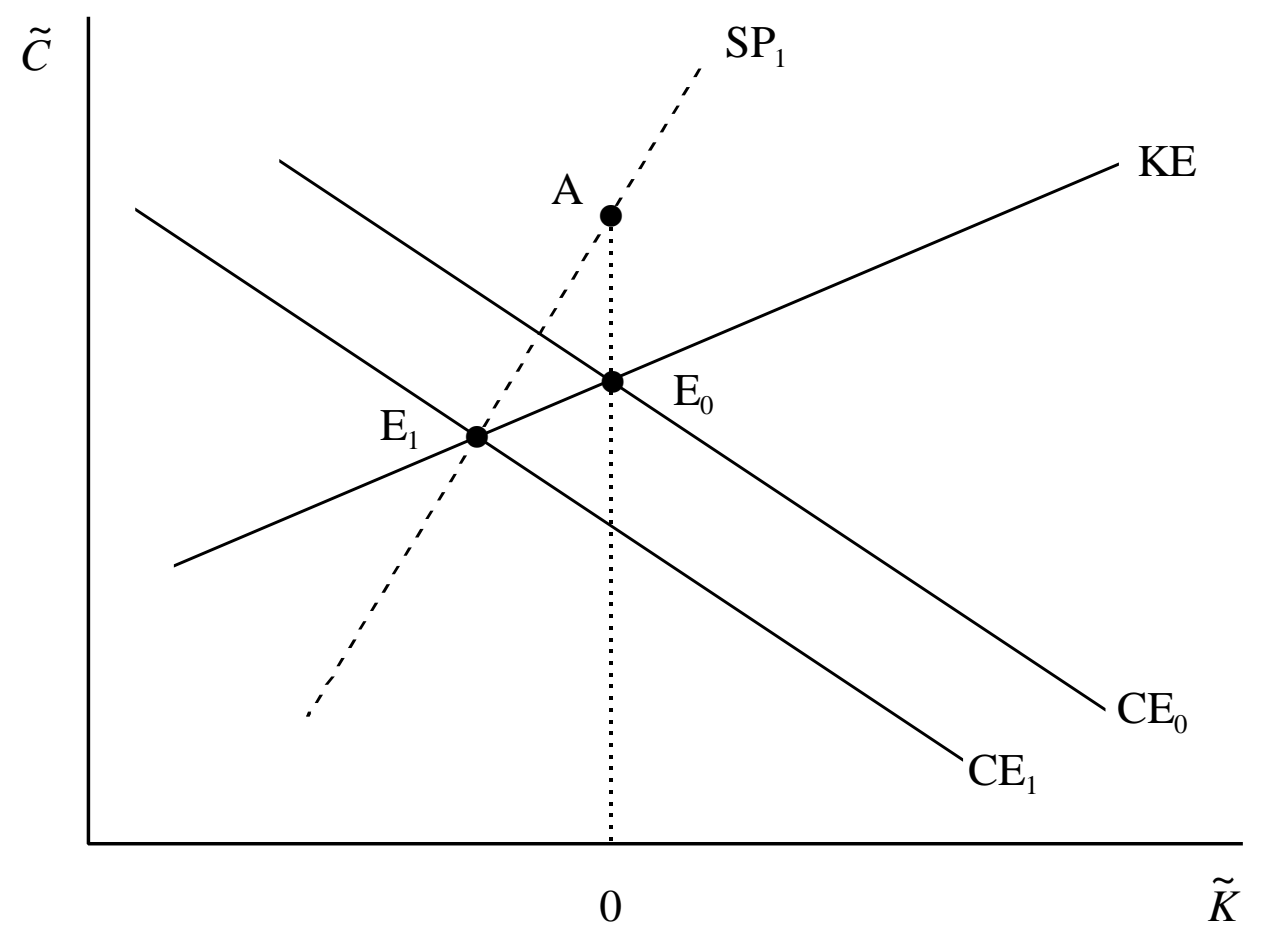

Figure 4: Increase in the Warm-Glow Motive 
$\tilde{C}(t)$

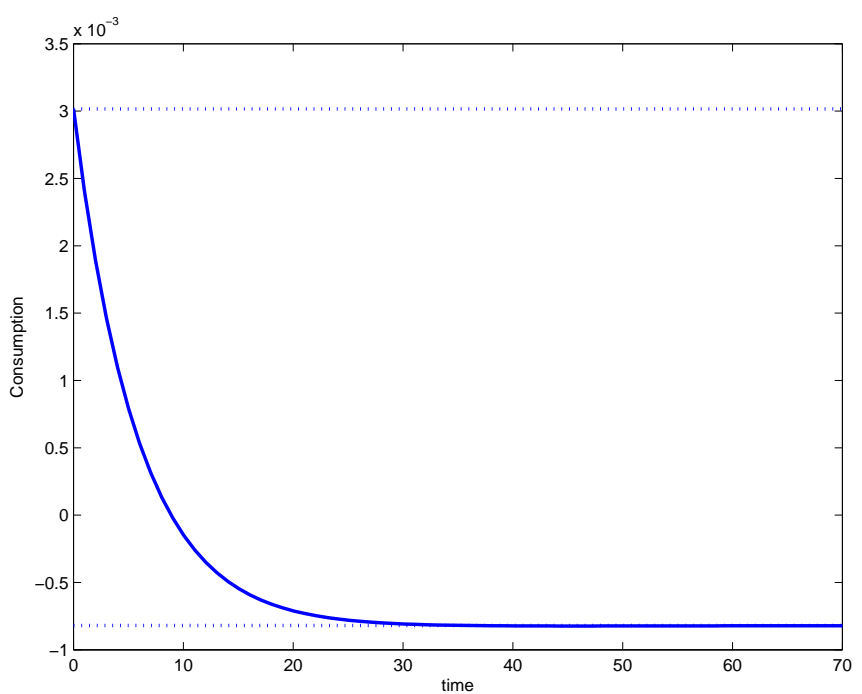

$\tilde{Q}(t)$

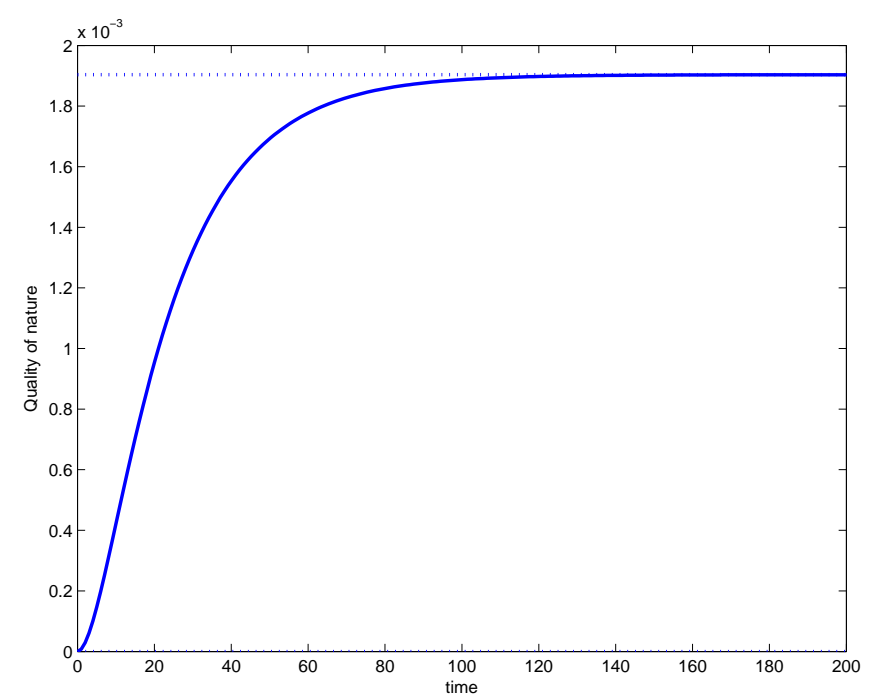

$\tilde{K}(t)$

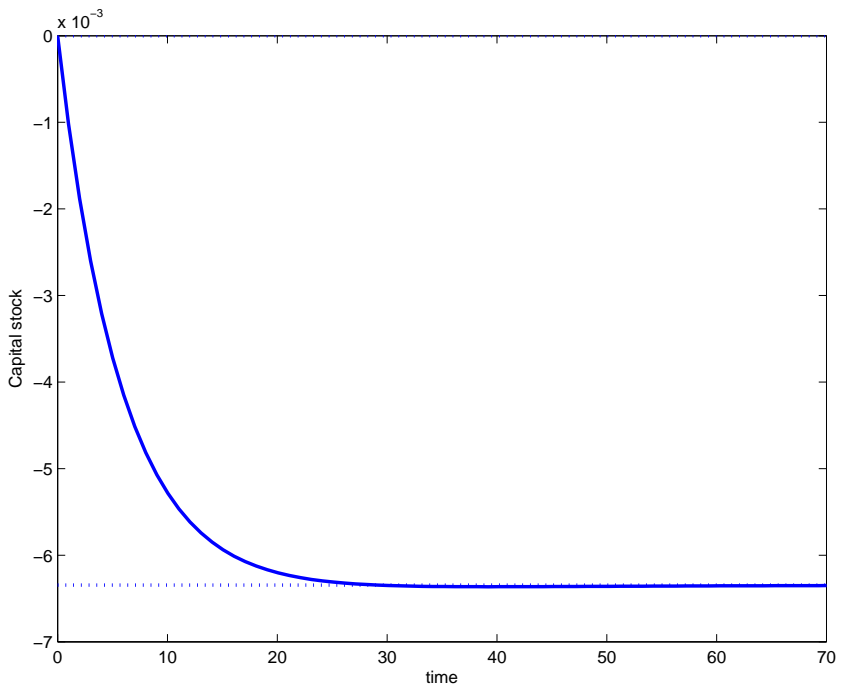

$\tilde{\theta}(t)$

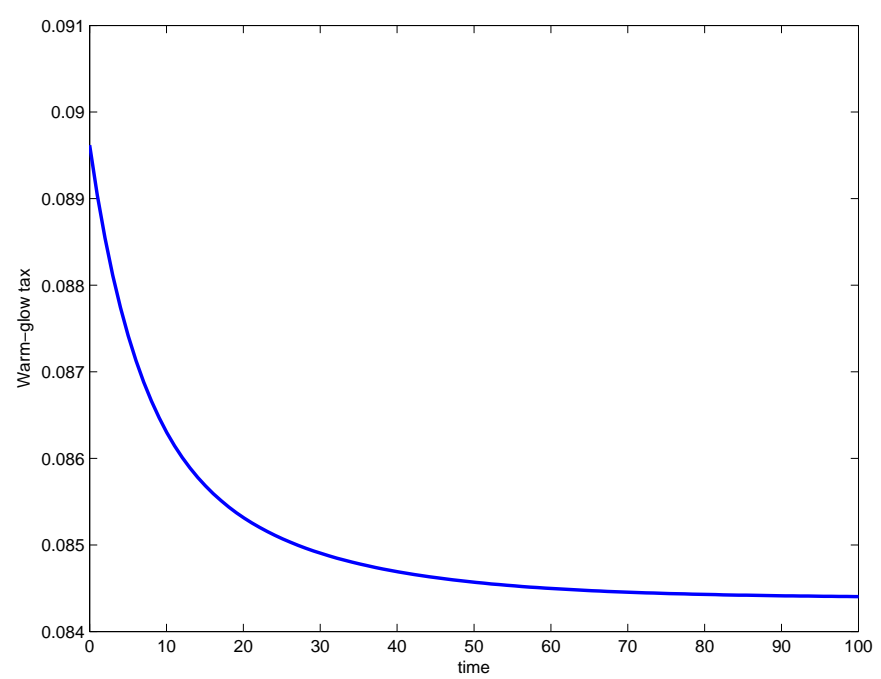

Figure 5: Transition Path for the Warm-Glow Shock (increase in $\gamma$ ) 


\section{Concluding remarks}

In this paper we explore the effects of socially responsible investment and public abatement on environmental quality and the economy. An important question we address is whether environmental policy is effective when consumers themselves have an incentive to (at least partially) internalize the environmental externality due to a "warm glow" motive. We show that socially responsible investment behaviour by households partially offsets the positive effects on environmental quality of public abatement policies. The "warm glow" motive results in socially responsible investment in the equity market. This in turn imposes an implicit tax on the value of the polluting firm. Abatement policy reduces resources available for consumption, which in turn lowers the implicit tax, leading to a larger capital stock and higher pollution. As a consequence, the abatement policy is (partly) offset via the implicit tax mechanism. 


\section{Appendix A: Household problem}

The household optimization program constitutes a non-standard optimal control problem which is solved by transforming it. The assets are perfect substitutes in the household portfolio so that we can define total assets, $a$, as follows:

$$
a=b+P_{e} e .
$$

By differentiating both sides of (A.1) with respect to time we obtain:

$$
\dot{a}=\dot{b}+P_{e} \dot{e}+\dot{P}_{e} e .
$$

By adding $\dot{P}_{e} e$ to both sides of (4) we obtain:

$$
\dot{a}=W+d-z-c+r b+e \dot{P}_{e} .
$$

By adding and deducting and $r P_{e} e$ to the right-hand side of (A.3) and noting (5) we obtain:

$$
\dot{a}=r a+W-z-c+\left(r_{e}-r\right) P_{e} e,
$$

where $r_{e} \equiv \dot{P}_{e} / P_{e}+\pi$. We now have a single aggregate state variable $(a)$ whose dynamic evolution must be determined.

The current-value Hamiltonian can be written as:

$$
\begin{aligned}
\mathcal{H} \equiv & \ln c-\beta \ln \left[1+\gamma^{*} e\right]+\zeta \ln Q \\
& +\lambda\left[r a+W-z-c+\left(r_{e}-r\right) P_{e} e\right]+\mu\left[a-b-P_{e} e\right],
\end{aligned}
$$

where $\gamma^{*} \equiv \gamma Y /(\bar{E} Q)$. The control variables are $c$, $e$, and $b$, the state variable is $a$, the co-state variable is $\lambda$, and the Lagrange multiplier is $\mu$. The key first-order (Kuhn-Tucker) conditions are:

$$
\begin{aligned}
& \frac{\partial \mathcal{H}}{\partial c}=\frac{1}{c}-\lambda=0, \\
& \frac{\partial \mathcal{H}}{\partial e}=-\frac{\beta}{1+p} \cdot \frac{\gamma Y}{\bar{E} Q}+\lambda P_{e}\left(r_{e}-r\right)-\mu P_{e} \leq 0, \quad e \geq 0, \quad e \frac{\partial \mathcal{H}}{\partial e}=0, \\
& \frac{\partial \mathcal{H}}{\partial b}=-\mu \leq 0, \quad b \geq 0, \quad b \frac{\partial \mathcal{H}}{\partial b}=0, \\
& \dot{\lambda}-\rho \lambda=-\frac{\partial \mathcal{H}}{\partial a}=-\lambda r-\mu .
\end{aligned}
$$

The felicity function, equation (A.2), implies that $c$ is essential, i.e. the marginal felicity of the first infinitesimal amount of consumption is infinite, $\lim _{c \rightarrow 0} \partial U / \partial c=+\infty$ so that consumption will always be strictly positive $(c>0)$. If some government bonds are held by the household $(b>0)$, then it follows from (A.7) that $\mu=0$. As a result, by combining (A.5) and (A.8) we obtain the Euler equation (6).

If some of the shares are also held $(e>0)$, then it follows from (A.5)-(A.6) that:

$$
r_{e}-r=\frac{\beta}{1+p} \frac{\gamma}{Q} \frac{c}{v}
$$

where $V \equiv P_{e} \bar{E}$ and $v \equiv V / Y$. This is equation (7) in the text. 


\section{Appendix B: Firm problem}

By assumption, the firm finances its investment plans by retained earnings:

$$
R E=I .
$$

By combining (10) and (B.1) and assuming that $R E(t)>0$ we obtain the following expression for dividends:

$$
D=\Pi-I .
$$

The market value for outstanding shares is $V=P_{e} \bar{E}$ so, by differentiating with respect to time, we obtain:

$$
\dot{V}=\dot{P}_{e} \bar{E} .
$$

The household arbitrage equation for shares, (A.6), can be written as:

$$
r=\frac{\dot{P}_{e}}{P_{e}}+\frac{D-\theta Y}{P_{e} \bar{E}},
$$

where $\theta$ is defined as follows:

$$
\theta \equiv \frac{\beta \gamma c}{(1+p) Q} .
$$

In its optimization plans, the firm takes the time path of $\theta$ as given. In equation (B.5), $-\theta Y$ represents a negative dividend in the form of pollution that is undesirable to the householdinvestors. By using (B.2)-(B.4) we obtain the fundamental differential equation for $V$ :

$$
\dot{V}=r V-[(1-\theta) F[K, L]-W L-I] .
$$

The key thing to note is that M-M still holds: dividends do not matter to the determination of the value of the firm.

Clearly, since the coefficient for $V$ on the right-hand side of (B.6) is positive, equation (B.6) is an unstable differential equation in $V$. The only economically sensible (no-bubble) solution is obtained by solving this differential equation forward in time and imposing the following terminal condition:

$$
\lim _{\tau \rightarrow \infty} V(\tau) \exp \left[-\int_{0}^{\tau} r(s) d s\right]=0 .
$$

This yields equation (14) in the text.

It is easy to show that $V(t)=K(t)$, i.e. $\theta$ does not influence the value of capital. The term in square brackets on the right-hand side of (B.6) can be written as:

$$
\begin{aligned}
{[\cdot] } & =(1-\theta) F[K, L]-W L-I \\
& =(1-\theta)\left[F_{K} K+F_{L} L\right]-W L-\dot{K}-\delta K \\
& =\left[(1-\theta) F_{K}-\delta\right] K+\left[(1-\theta) F_{L}-W\right] L-\dot{K} \\
& =r K-\dot{K},
\end{aligned}
$$


where we have used (15)-(16). By using this result in (B.6) we immediately find that $V(t)=$ $K(t)$.

\section{Appendix C: Comparative dynamics}

For the most general case, the $\bar{\Delta}$ matrix can be written as:

$$
\bar{\Delta}=\left[\begin{array}{ccc}
\delta_{11} & \delta_{12}+\alpha \varepsilon_{Y} \eta_{13} & \eta_{13} \\
\delta_{21} & \delta_{22} & 0 \\
0 & -\alpha \varepsilon_{Y} \mu & -\mu
\end{array}\right]
$$

where $\delta_{i j}$ are the typical elements of the $\Delta$ matrix, and $\eta_{13} \equiv \alpha \hat{y} \hat{\theta} \omega_{Q}$. By multiplying the third column by $\alpha \varepsilon_{Y}$ and deducting the resulting column from the second column we obtain for $|\bar{\Delta}|$ :

$$
|\bar{\Delta}|=-\frac{\mu}{\alpha \varepsilon_{Y}} \cdot\left|\begin{array}{ccc}
\delta_{11} & \delta_{12} & \alpha \varepsilon_{Y} \eta_{13} \\
\delta_{21} & \delta_{22} & 0 \\
0 & 0 & \alpha \varepsilon_{Y}
\end{array}\right|=-\mu \cdot|\Delta|,
$$

where $|\Delta|$ is given in (21) in the text. The adjoint matrix is given by:

$$
\operatorname{adj} \bar{\Delta}=\left[\begin{array}{ccc}
-\mu \delta_{22} & \mu \delta_{12} & -\eta_{13} \delta_{22} \\
\mu \delta_{21} & -\mu \delta_{11} & \eta_{13} \delta_{21} \\
-\alpha \varepsilon_{Y} \mu \delta_{21} & \alpha \varepsilon_{Y} \mu \delta_{11} & |\Delta|-\alpha \varepsilon_{Y} \delta_{21} \eta_{13}
\end{array}\right],
$$

so that $\bar{\Delta}^{-1}$ is equal to:

$$
\bar{\Delta}^{-1}=\frac{1}{|\Delta|} \cdot\left[\begin{array}{ccc}
\delta_{22} & -\delta_{12} & \eta_{13} \delta_{22} / \mu \\
-\delta_{21} & \delta_{11} & -\eta_{13} \delta_{21} / \mu \\
\alpha \varepsilon_{Y} \delta_{21} & -\alpha \varepsilon_{Y} \delta_{11} & {\left[\alpha \varepsilon_{Y} \delta_{21} \eta_{13}-|\Delta|\right] / \mu}
\end{array}\right] .
$$

For the flow interpetation we have $\mu \rightarrow \infty$, so that the third column vanishes. In view of the definition of $\eta_{13}$, we can write $\bar{\Gamma}$ as:

$$
\bar{\Gamma} \equiv\left[\begin{array}{l}
-\eta_{13} \tilde{\gamma} \\
-\hat{y} \omega_{G} \tilde{G} \\
\mu \varepsilon_{G} \tilde{G}
\end{array}\right]
$$

The characteristic polynomial of $\bar{\Delta}$ is:

$$
|\bar{\Lambda}(s)| \equiv\left|s \mathrm{I}_{3}-\bar{\Delta}\right|=(s+\mu) \Psi(s)-\alpha \varepsilon_{Y} \delta_{21} \eta_{13} s,
$$

where $\bar{\Lambda}(s) \equiv s \mathrm{I}_{3}-\bar{\Delta}, \Psi(s)$ is the characteristic polynomial of $\Delta$ :

$$
\Psi(s) \equiv\left|s \mathrm{I}_{2}-\Delta\right|=s^{2}-\operatorname{tr} \Delta \cdot s+|\Delta| .
$$




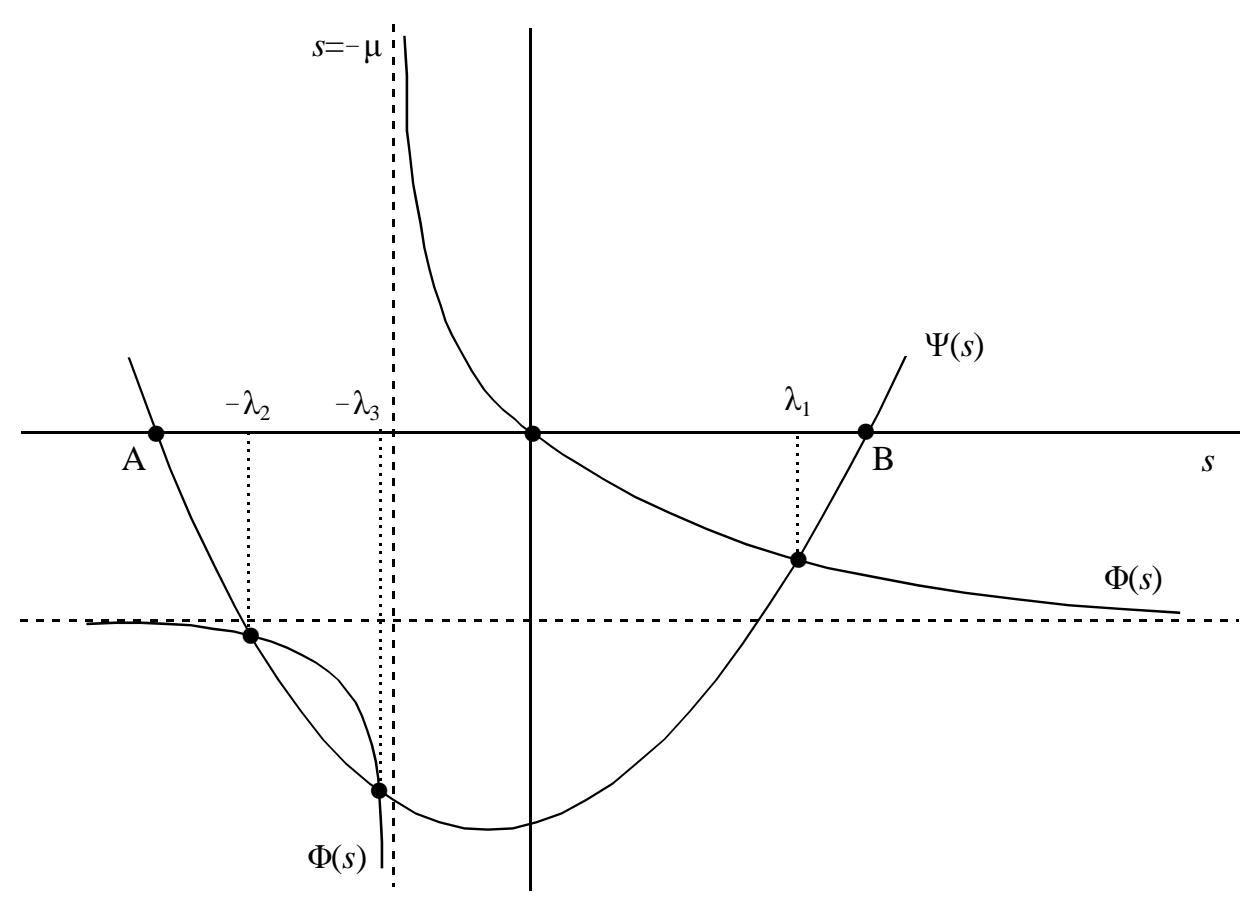

Figure C.1: Characteristic Roots

Denote the roots of $\Delta$ by $\lambda_{1}$ and $-\lambda_{2}$. Clearly, the roots of $\bar{\Delta}$ are not $s=-\mu$, and the roots of $\Delta\left(\lambda_{1}\right.$ and $\left.-\lambda_{2}\right)$. The roots of $\Delta$ are implicitly defined by:

$$
\Psi(s)=\alpha \varepsilon_{Y} \delta_{21} \eta_{13} \frac{s}{s+\mu}[\equiv \Phi(s)]
$$

Figure 5 depicts the location of the characteristic roots, assuming that the speed of adjustment of nature is lower than the speed of adjustment in the economic subsystem. It is clear from (C.7) that $\Psi(s)$ is a parabola, featuring $\Psi(s)=|\Delta|<0$ and roots that alternate in sign. These roots, $\lambda_{1}$ and $-\lambda_{2}$, are located at points $\mathrm{A}$ in $\mathrm{B}$ in the figure. If $\eta_{13}$ were zero (for example, if $\omega_{Q}=0$ ), then there would only be one-way interaction between the economy and nature, as in Bovenberg and Heijdra (1998). The roots would simply be $-\bar{\lambda}_{3}=-\mu$ and the roots of $\Psi(s)$, i.e. $\lambda_{1}$ and $-\lambda_{2}$. Here however, we assume that $\eta_{13}>0$ (because $\omega_{Q}>0$ ) so the economy affects nature and vice versa. It is clear from (C.8) that $\Phi(s)$ is downward sloping an features two branches-one in the third quadrant and one in the first quadrant (the horizontal and vertical asymptotes are at, respectively $s=-\mu$ and $\Phi(s)=\alpha \varepsilon_{Y} \delta_{21} \eta_{13}<0$. In the figure we have drawn the case for which all roots are real: $\Psi(s)$ intersects $\Phi(s)$ twice in the third quadrant and once in the first. For some parameter values, the intersection in the third quadrant vanishes and the stable roots are complex conjugate, with negative real parts. 


\section{Long-run effects}

By using (22), (C.4), and (C.5) we find the long-run effects:

$$
\begin{aligned}
{\left[\begin{array}{c}
\tilde{C}(\infty) \\
\tilde{K}(\infty) \\
\tilde{Q}(\infty)
\end{array}\right]=} & -\bar{\Delta}^{-1} \cdot \bar{\Gamma}=\frac{\eta_{13}}{|\Delta|} \cdot\left[\begin{array}{c}
\delta_{22} \\
-\delta_{21} \\
\alpha \varepsilon_{Y} \delta_{21}
\end{array}\right] \cdot \tilde{\gamma} \\
& -\frac{1}{|\Delta|} \cdot\left[\begin{array}{l}
\delta_{12} \hat{y} \omega_{G}+\eta_{13} \delta_{22} \varepsilon_{G} \\
-\delta_{11} \hat{y} \omega_{G}-\eta_{13} \delta_{21} \varepsilon_{G} \\
\alpha \varepsilon_{Y} \delta_{11} \hat{y} \omega_{G}+\left[\alpha \varepsilon_{Y} \delta_{21} \eta_{13}-|\Delta|\right] \varepsilon_{G}
\end{array}\right] \cdot \tilde{G}
\end{aligned}
$$

Recall that $|\Delta|=-\lambda_{1} \lambda_{2}$.

\section{Impact effects}

By taking the Laplace transform of $(22)$ and noting that $\tilde{K}(0)=\tilde{Q}(0)=0$ we obtain:

$$
\bar{\Lambda}(s)\left[\begin{array}{l}
\mathcal{L}\{\tilde{C}, s\} \\
\mathcal{L}\{\tilde{K}, s\} \\
\mathcal{L}\{\tilde{Q}, s\}
\end{array}\right]=\left[\begin{array}{l}
\tilde{C}(0)-\eta_{13} \mathcal{L}\{\tilde{\gamma}, s\} \\
-\hat{y} \omega_{G} \mathcal{L}\{\tilde{G}, s\} \\
\mu \varepsilon_{G} \mathcal{L}\{\tilde{G}, s\}
\end{array}\right]
$$

where $\bar{\Lambda}(s) \equiv s \mathrm{I}_{3}-\bar{\Delta}$. We assume that the roots are real, i.e. $\bar{\lambda}_{1}>0,-\bar{\lambda}_{2}<0$, and $-\bar{\lambda}_{3}<0$. We know that:

$$
\bar{\Lambda}(s)^{-1} \equiv \frac{1}{\left(s-\bar{\lambda}_{1}\right)\left(s+\bar{\lambda}_{2}\right)\left(s+\bar{\lambda}_{3}\right)} \operatorname{adj} \bar{\Lambda}(s),
$$

where $\operatorname{adj} \bar{\Lambda}(s)$ is the adjoint matrix of $\bar{\Lambda}(s)$. By pre-multiplying both sides of (C.10) by $\bar{\Lambda}(s)^{-1}$ and rearranging we obtain the following expression in Laplace transforms:

$$
\left(s+\bar{\lambda}_{2}\right)\left(s+\bar{\lambda}_{3}\right)\left[\begin{array}{c}
\mathcal{L}\{\tilde{C}, s\} \\
\mathcal{L}\{\tilde{K}, s\} \\
\mathcal{L}\{\tilde{Q}, s\}
\end{array}\right]=\frac{1}{s-\bar{\lambda}_{1}} \cdot \operatorname{adj} \bar{\Lambda}(s)\left[\begin{array}{l}
\tilde{C}(0)-\eta_{13} \mathcal{L}\{\tilde{\gamma}, s\} \\
-\hat{y} \omega_{G} \mathcal{L}\{\tilde{G}, s\} \\
\mu \varepsilon_{G} \mathcal{L}\{\tilde{G}, s\}
\end{array}\right]
$$

The $\operatorname{adj} \bar{\Lambda}(s)$ matrix is equal to:

$$
\operatorname{adj} \bar{\Lambda}(s) \equiv\left[\begin{array}{ccc}
(s+\mu)\left(s-\delta_{22}\right) & \alpha \varepsilon_{Y} \eta_{13} s+\delta_{12}(s+\mu) & \eta_{13}\left(s-\delta_{22}\right) \\
(s+\mu) \delta_{21} & (s+\mu)\left(s-\delta_{11}\right) & \eta_{13} \delta_{21} \\
-\alpha \varepsilon_{Y} \mu \delta_{21} & -\alpha \varepsilon_{Y} \mu\left(s-\delta_{11}\right) & \Psi(s)-\alpha \varepsilon_{Y} \delta_{21} \eta_{13}
\end{array}\right] .
$$

The jump in $\tilde{C}(0)$ is such that the right-hand side of (C.12) is of the $0 \div 0$ type for the unstable root, $\bar{\lambda}_{1}$. Using the second row of $\operatorname{adj} \bar{\Lambda}(s)$, for example, we get for $s=\bar{\lambda}_{1}$ :

$$
\begin{aligned}
0= & \left(\bar{\lambda}_{1}+\mu\right) \delta_{21}\left[\tilde{C}(0)-\eta_{13} \mathcal{L}\left\{\tilde{\gamma}, \bar{\lambda}_{1}\right\}\right]-\left(\bar{\lambda}_{1}+\mu\right)\left(\bar{\lambda}_{1}-\delta_{11}\right) \hat{y} \omega_{G} \mathcal{L}\left\{\tilde{G}, \bar{\lambda}_{1}\right\} \\
& +\eta_{13} \delta_{21} \mu \varepsilon_{G} \mathcal{L}\left\{\tilde{G}, \bar{\lambda}_{1}\right\} .
\end{aligned}
$$


Solving for $\tilde{C}(0)$ we thus find:

$$
\tilde{C}(0)=\eta_{13} \mathcal{L}\left\{\tilde{\gamma}, \bar{\lambda}_{1}\right\}+\left[\frac{\left(\bar{\lambda}_{1}+\mu\right)\left(\bar{\lambda}_{1}-\delta_{11}\right) \hat{y} \omega_{G}-\eta_{13} \delta_{21} \mu \varepsilon_{G}}{\left(\bar{\lambda}_{1}+\mu\right) \delta_{21}}\right] \mathcal{L}\left\{\tilde{G}, \bar{\lambda}_{1}\right\} .
$$

For stepwise shocks we have that $\mathcal{L}\{\tilde{\gamma}, s\}=\tilde{\gamma} / s$ and $\mathcal{L}\{\tilde{G}, s\}=\tilde{G} / s$, a result we impose from here on.

\section{Transitional dynamics}

We can write the first row of $(\mathrm{C} .12)$ as $\left(s+\bar{\lambda}_{2}\right)\left(s+\bar{\lambda}_{3}\right) \mathcal{L}\{\tilde{C}, s\}=\Gamma_{C} /\left(s-\bar{\lambda}_{1}\right)$, with:

$$
\begin{aligned}
\Gamma_{C} \equiv & (s+\mu)\left(s-\delta_{22}\right)\left[\tilde{C}(0)-\eta_{13} \mathcal{L}\{\tilde{\gamma}, s\}\right]-\left[\alpha \varepsilon_{Y} \eta_{13} s+\delta_{12}(s+\mu)\right] \hat{y} \omega_{G} \mathcal{L}\{\tilde{G}, s\} \\
& +\eta_{13}\left(s-\delta_{22}\right) \mu \varepsilon_{G} \mathcal{L}\{\tilde{G}, s\} .
\end{aligned}
$$

We also know that $\tilde{C}(0)$ is such that:

$$
\begin{array}{rlr}
0 \equiv & \left(\bar{\lambda}_{1}+\mu\right)\left(\bar{\lambda}_{1}-\delta_{22}\right)\left[\tilde{C}(0)-\eta_{13} \mathcal{L}\left\{\tilde{\gamma}, \bar{\lambda}_{1}\right\}\right]-\left[\alpha \varepsilon_{Y} \eta_{13} \bar{\lambda}_{1}+\delta_{12}\left(\bar{\lambda}_{1}+\mu\right)\right] \hat{y} \omega_{G} \mathcal{L}\left\{\tilde{G}, \bar{\lambda}_{1}\right\} \\
& +\eta_{13}\left(\bar{\lambda}_{1}-\delta_{22}\right) \mu \varepsilon_{G} \mathcal{L}\left\{\tilde{G}, \bar{\lambda}_{1}\right\} .
\end{array}
$$

Lemma C.1 contains some useful results needed to simplify the expression for $\Gamma_{C} /\left(s-\bar{\lambda}_{1}\right)$.

Lemma C.1 Define $\Xi(s) \equiv s^{2}+\xi_{1} s+\xi_{0}$. Then the following results can be obtained:

$$
\begin{aligned}
\frac{\Xi(s)-\Xi(x)}{s-x} & =s+x+\xi_{1}, \\
\frac{\Xi(s) / s-\Xi(x) / x}{s-x} & =1-\frac{\xi_{0}}{s x},
\end{aligned}
$$

Proof: by straightforward substitutions. .

After some straightforward manipulations we obtain:

$$
\begin{aligned}
\frac{\Gamma_{C}}{s-\bar{\lambda}_{1}}= & {\left[s+\bar{\lambda}_{1}+\mu-\delta_{22}\right] \cdot \tilde{C}(0)-\frac{s \bar{\lambda}_{1}+\mu \delta_{22}}{s \bar{\lambda}_{1}} \cdot \eta_{13} \tilde{\gamma} } \\
& +\frac{\mu \delta_{12}}{s \bar{\lambda}_{1}} \cdot \hat{y} \omega_{G} \tilde{G}+\frac{\delta_{22}}{s \bar{\lambda}_{1}} \cdot \eta_{13} \mu \varepsilon_{G} \tilde{G} .
\end{aligned}
$$

By substituting (C.18) into the expression for $\mathcal{L}\{\tilde{C}, s\}$ we thus obtain:

$$
\begin{aligned}
\mathcal{L}\{\tilde{C}, s\}= & \frac{s+\bar{\lambda}_{1}+\mu-\delta_{22}}{\left(s+\bar{\lambda}_{2}\right)\left(s+\bar{\lambda}_{3}\right)} \cdot \tilde{C}(0)-\frac{s \bar{\lambda}_{1}+\mu \delta_{22}}{s\left(s+\bar{\lambda}_{2}\right)\left(s+\bar{\lambda}_{3}\right)} \cdot \frac{\eta_{13} \tilde{\gamma}}{\bar{\lambda}_{1}} \\
& +\frac{\delta_{12} \hat{y} \omega_{G}+\delta_{22} \eta_{13} \varepsilon_{G}}{s\left(s+\bar{\lambda}_{2}\right)\left(s+\bar{\lambda}_{3}\right)} \cdot \frac{\mu \tilde{G}}{\bar{\lambda}_{1}} .
\end{aligned}
$$

To check, we use the initial-value and final-value theorems of the Laplace transform to compute, respectively, the impact and long-run effects:

$$
\begin{aligned}
\lim _{s \rightarrow \infty} s \mathcal{L}\{\tilde{C}, s\} & =\tilde{C}(0) \lim _{s \rightarrow \infty} \frac{s^{2}+\left(\bar{\lambda}_{1}+\mu-\delta_{22}\right) s}{\left(s+\bar{\lambda}_{2}\right)\left(s+\bar{\lambda}_{3}\right)}=\tilde{C}(0), \\
\lim _{s \rightarrow 0} s \mathcal{L}\{\tilde{C}, s\} & =-\frac{\mu \delta_{22}}{\bar{\lambda}_{1} \bar{\lambda}_{2} \bar{\lambda}_{3}} \cdot \eta_{13} \tilde{\gamma}+\frac{\delta_{12} \hat{y} \omega_{G}+\delta_{22} \eta_{13} \varepsilon_{G}}{\bar{\lambda}_{2} \bar{\lambda}_{3}} \cdot \frac{\mu \tilde{G}}{\bar{\lambda}_{1}}=\tilde{C}(\infty) .
\end{aligned}
$$


It is easy to see that (C.21) coincides with the expression in (C.9)- the key thing to note is that $\bar{\lambda}_{1} \bar{\lambda}_{2} \bar{\lambda}_{3}=-\mu|\Delta|$. Note that the term in front of (C.19) can be simplified by splitting it:

$$
\begin{aligned}
\frac{s+\bar{\lambda}_{1}+\mu-\delta_{22}}{\left(s+\bar{\lambda}_{2}\right)\left(s+\bar{\lambda}_{3}\right)} & =\frac{1}{s+\bar{\lambda}_{2}}+\frac{\bar{\lambda}_{1}-\bar{\lambda}_{3}+\mu-\delta_{22}}{\left(s+\bar{\lambda}_{2}\right)\left(s+\bar{\lambda}_{3}\right)} \\
& =\frac{1}{s+\bar{\lambda}_{2}}+\frac{\rho+\bar{\lambda}_{2}-\delta_{22}}{\left(s+\bar{\lambda}_{2}\right)\left(s+\bar{\lambda}_{3}\right)},
\end{aligned}
$$

where we have used the fact that $\bar{\lambda}_{1}-\bar{\lambda}_{2}-\bar{\lambda}_{3}=\rho-\mu$.

Using the same approach we find that:

$$
\begin{aligned}
\mathcal{L}\{\tilde{K}, s\}= & \frac{\delta_{21}}{\left(s+\bar{\lambda}_{2}\right)\left(s+\bar{\lambda}_{3}\right)} \cdot \tilde{C}(0)+\frac{1}{s\left(s+\bar{\lambda}_{2}\right)\left(s+\bar{\lambda}_{3}\right)} \cdot \frac{\mu \delta_{21} \eta_{13}}{\bar{\lambda}_{1}} \tilde{\gamma} \\
& -\frac{s \bar{\lambda}_{1}+\mu \delta_{11}}{s\left(s+\bar{\lambda}_{2}\right)\left(s+\bar{\lambda}_{3}\right)} \cdot \frac{\hat{y} \omega_{G}}{\bar{\lambda}_{1}} \tilde{G}-\frac{\delta_{21}}{s\left(s+\bar{\lambda}_{2}\right)\left(s+\bar{\lambda}_{3}\right)} \cdot \frac{\eta_{13} \mu \varepsilon_{G}}{\bar{\lambda}_{1}} \tilde{G}, \\
\mathcal{L}\{\tilde{Q}, s\}= & -\frac{\alpha \varepsilon_{Y}}{s\left(s+\bar{\lambda}_{2}\right)\left(s+\bar{\lambda}_{3}\right)} \cdot \frac{\mu \delta_{21} \eta_{13}}{\bar{\lambda}_{1}} \tilde{\gamma}+\frac{\alpha \varepsilon_{Y} \mu \delta_{11}}{s\left(s+\bar{\lambda}_{2}\right)\left(s+\bar{\lambda}_{3}\right)} \cdot \frac{\hat{y} \omega_{G}}{\bar{\lambda}_{1}} \tilde{G} \\
& +\frac{s \bar{\lambda}_{1}+\lambda_{1} \lambda_{2}+\alpha \varepsilon_{Y} \delta_{21} \eta_{13}}{s\left(s+\bar{\lambda}_{2}\right)\left(s+\bar{\lambda}_{3}\right)} \cdot \frac{\mu \varepsilon_{G}}{\bar{\lambda}_{1}} \tilde{G} .
\end{aligned}
$$

Equation (C.23) can be written in an alternative form by substituting the expression for $\tilde{C}(0)$, stated in (C.15), and simplifying:

$$
\begin{aligned}
\mathcal{L}\{\tilde{K}, s\}= & \frac{s+\mu}{s\left(s+\bar{\lambda}_{2}\right)\left(s+\bar{\lambda}_{3}\right)} \cdot \frac{\delta_{21} \eta_{13}}{\bar{\lambda}_{1}} \tilde{\gamma}-\frac{s+\mu}{s\left(s+\bar{\lambda}_{2}\right)\left(s+\bar{\lambda}_{3}\right)} \cdot \frac{\delta_{11} \hat{y} \omega_{G}}{\bar{\lambda}_{1}} \tilde{G} \\
& -\frac{\bar{\lambda}_{1}+s+\mu}{s\left(s+\bar{\lambda}_{2}\right)\left(s+\bar{\lambda}_{3}\right)} \cdot \frac{\eta_{13} \delta_{21} \mu \varepsilon_{G}}{\bar{\lambda}_{1}} \tilde{G} .
\end{aligned}
$$

Glancing at (C.19) and (C.23)-(C.25), it is clear that there are only two types of Laplace transforms for which we need to know the inverse. These inverses are covered in Lemma's C.2 and C.3.

Lemma C.2 Let $-\bar{\lambda}_{2}$ and $-\bar{\lambda}_{3}$ denote stable characteristics root. For the complex case, we write these roots as $-\bar{\lambda}_{2} \equiv-\lambda^{*}+\theta i$ and $-\bar{\lambda}_{3} \equiv-\lambda^{*}-\theta i$, where $\lambda^{*}>0$ and $i$ is the imaginary unit. Define the following Laplace transform:

$$
\mathcal{L}\{\mathbf{T}(t), s\} \equiv \frac{1}{\left(s+\bar{\lambda}_{2}\right)\left(s+\bar{\lambda}_{3}\right)} .
$$

Then $\mathbf{T}(t)$ is a temporary transition term. (i) For real roots we obtain:

$$
\begin{aligned}
\mathbf{T}(t) & \equiv \frac{e^{-\bar{\lambda}_{2} t}-e^{-\bar{\lambda}_{3} t}}{\bar{\lambda}_{3}-\bar{\lambda}_{2}}, \quad\left(\text { for } \bar{\lambda}_{2} \neq \bar{\lambda}_{3}\right) \\
& \equiv t \cdot e^{-\bar{\lambda}_{2} t}, \quad\left(\text { for } \bar{\lambda}_{2}=\bar{\lambda}_{3}\right)
\end{aligned}
$$

(ii) For complex roots:

$$
\mathbf{T}(t) \equiv \frac{1}{\theta} \cdot e^{-\lambda^{*} t} \cdot \sin (\theta t) .
$$

(iii) Properties: $\mathbf{T}(0)=0$ and $\lim _{t \rightarrow \infty} \mathbf{T}(t)=0$. 
Proof: Straightforward. For the complex case recall that $e^{-\bar{\lambda}_{2} t}=e^{-\lambda^{*} t}[\cos (\theta t)+i \sin (\theta t)]$, $\bar{\lambda}_{3}-\bar{\lambda}_{2}=2 \theta i$, and $e^{-\bar{\lambda}_{3} t}=e^{-\lambda^{*} t}[\cos (\theta t)-i \sin (\theta t)]$.

Lemma C.3 Let $-\bar{\lambda}_{2}$ and $-\bar{\lambda}_{3}$ denote stable characteristics root. For the complex case, we write these roots as $-\bar{\lambda}_{2} \equiv-\lambda^{*}-\theta i$ and $-\bar{\lambda}_{3} \equiv-\lambda^{*}+\theta i$, where $\lambda^{*}>0$ and $i$ is the imaginary unit. Define the following Laplace transform:

$$
\mathcal{L}\{\mathbf{A}(t), s\} \equiv \frac{1}{s\left(s+\bar{\lambda}_{2}\right)\left(s+\bar{\lambda}_{3}\right)} .
$$

Then $\mathbf{A}(t)$ is an adjustment term. (i) For real roots we obtain:

$$
\begin{aligned}
\mathbf{A}(t) & \equiv \frac{1}{\bar{\lambda}_{2} \bar{\lambda}_{3}} \cdot\left[1-\frac{\bar{\lambda}_{3}}{\bar{\lambda}_{3}-\bar{\lambda}_{2}} e^{-\bar{\lambda}_{2} t}+\frac{\bar{\lambda}_{2}}{\bar{\lambda}_{3}-\bar{\lambda}_{2}} e^{-\bar{\lambda}_{3} t}\right], \quad\left(\text { for } \bar{\lambda}_{2} \neq \bar{\lambda}_{3}\right) \\
& \equiv \frac{1}{\bar{\lambda}_{2} \bar{\lambda}_{3}} \cdot\left[1-e^{-\bar{\lambda}_{2} t}-\bar{\lambda}_{2} \cdot t \cdot e^{-\bar{\lambda}_{2} t}\right], \quad\left(\text { for } \bar{\lambda}_{2}=\bar{\lambda}_{3}\right)
\end{aligned}
$$

(ii) For complex roots:

$$
\mathbf{A}(t) \equiv \frac{1}{\left(\lambda^{*}\right)^{2}+\theta^{2}}\left[1-e^{-\lambda^{*} t}\left(\cos (\theta t)+\frac{\lambda^{*}}{\theta} \sin (\theta t)\right)\right] .
$$

(iii) Properties: $\mathbf{A}(0)=0$ and $\lim _{t \rightarrow \infty} \mathbf{A}(t)=1 /\left[\left(\lambda^{*}\right)^{2}+\theta^{2}\right]>0$.

Proof: First we state some useful results (for distinct roots):

$$
\begin{aligned}
\frac{1}{s\left(s+\bar{\lambda}_{2}\right)\left(s+\bar{\lambda}_{3}\right)} & =\frac{1}{\bar{\lambda}_{3}-\bar{\lambda}_{2}}\left[\frac{1}{s\left(s+\bar{\lambda}_{2}\right)}-\frac{1}{s\left(s+\bar{\lambda}_{3}\right)}\right] \\
& =\frac{1}{\bar{\lambda}_{3}-\bar{\lambda}_{2}}\left[\frac{1}{\bar{\lambda}_{2}}\left(\frac{1}{s}-\frac{1}{s+\bar{\lambda}_{2}}\right)-\frac{1}{\bar{\lambda}_{3}}\left(\frac{1}{s}-\frac{1}{s+\bar{\lambda}_{3}}\right)\right] .
\end{aligned}
$$

It follows that:

$$
\mathcal{L}^{-1}\{\cdot\}=\frac{1}{\bar{\lambda}_{3}-\bar{\lambda}_{2}}\left[\frac{1}{\bar{\lambda}_{2}}\left[1-e^{-\bar{\lambda}_{2} t}\right]-\frac{1}{\bar{\lambda}_{3}}\left[1-e^{-\bar{\lambda}_{3} t}\right]\right] .
$$

For the complex case we thus get:

$$
\begin{aligned}
\mathcal{L}^{-1}\{\cdot\} & =\frac{1}{\bar{\lambda}_{3}-\bar{\lambda}_{2}}\left[\frac{1}{\bar{\lambda}_{2}}\left(1-e^{-\lambda^{*} t}[\cos (\theta t)+i \sin (\theta t)]\right)-\frac{1}{\bar{\lambda}_{3}}\left(1-e^{-\lambda^{*} t}[\cos (\theta t)-i \sin (\theta t)]\right)\right] \\
& =\frac{1}{\bar{\lambda}_{3}-\bar{\lambda}_{2}}\left[e^{-\lambda^{*} t}\left(\frac{-\left(\bar{\lambda}_{3}-\bar{\lambda}_{2}\right) \cos (\theta t)+\left(\bar{\lambda}_{3}+\bar{\lambda}_{2}\right) i \sin (\theta t)}{\bar{\lambda}_{2} \bar{\lambda}_{3}}\right)+\frac{\bar{\lambda}_{3}-\bar{\lambda}_{2}}{\bar{\lambda}_{2} \bar{\lambda}_{3}}\right] \\
& =\frac{1}{\left(\lambda^{*}\right)^{2}+\theta^{2}}\left[1-e^{-h^{*} t}\left(\cos (\theta t)+\frac{\lambda^{*}}{\theta} \sin (\theta t)\right)\right],
\end{aligned}
$$

where we have used $\bar{\lambda}_{3}-\bar{\lambda}_{2}=2 \theta i, \bar{\lambda}_{3}+\bar{\lambda}_{2}=2 \lambda^{*}, \bar{\lambda}_{2} \bar{\lambda}_{3}=\left(\lambda^{*}\right)^{2}+\theta^{2}$ in the final step. For repeated real roots we can just use l'Hopitals Rule. 


\section{References}

Andreoni, J. (1990). Impure altruism and donations to public goods: A theory of warm-glow giving. Economic Journal, 100:464-477.

Bansal, S. and Gangopadhyay, S. (2003). Tax/subsidy policies in the presence of environmentally aware consumers. Journal of Environmental Economics and Management, 45:333355.

Beltratti, A. (2005). Capital market equilibrium with externalities, production and heterogeneous agents. Journal of Banking and Finance, 29:3061-3073.

Bjørner, T., Hansen, L., and Russel, C. (2004). Environmental labeling and consumers' choice: An empirical analysis of the effect of the nordic swan. Journal of Environmental Economics and Management, 47:411-434.

Bovenberg, A. L. and Heijdra, B. J. (1998). Environmental tax policy and intergenerational distribution. Journal of Public Economics, 67:1-24.

Dam, L. (2006a). Corporate social responsibility in a general equilibrium stock market model: Solving the financial performance puzzle. CCSO Working Paper Series 200603, University of Groningen, Groningen.

Dam, L. (2006b). Firm valuation in an environmental overlapping generations model. CCSO Working Paper Series 200601, University of Groningen, Groningen.

Diamond, P. A. (1965). National debt in a neoclassical growth model. American Economic Review, 55:1126-1150.

Diamond, P. A. (1967). The role of a stock market in a general equilibrium model with technological uncertainty. American Economic Review, 57:759-776.

Fama, E. F. and French, K. R. (2005). Disagreement, tastes and asset prices. CRSP Working Paper 552, CRSP. Available at SSRN: http://ssrn. com/abstract=502605.

Heal, G. (2003). Bundling biodiversity. Journal of the European Economic Association, 1:553-560.

Heinkel, R., Kraus, A., and Zechner, J. (2001). The effect of green investment on corporate behavior. Journal of Financial and Quantitative Analysis, 36:431-449.

Hong, H. and Kacperczyk, M. (2005). The price of sin: The effects of social norms on markets. Working paper, Department of Economics, Princeton University.

John, A. and Pecchenino, R. A. (1994). An overlapping generations model of growth and the environment. Economic Journal, 104:1393-1410. 
Kriström, B. and Lundgren, T. (2003). Abatement investment and green goodwill. Applied Economics, 13:1915-1921.

Margolis, J. D. and Walsh, J. P. (2001). People and Profits? The Search for a Link Between a Company's Social and Financial Performance. Erlbaum, Greenwich, CT.

Merton, R. C. (1987). A simple model of capital market equilibrium with incomplete information. Journal of Finance, 42:483-510.

Nyborg, K., Howarth, R. B., and Brekke, K. A. (2006). Green consumers and public policy: On socially contingent moral motivation. Resource and Energy Economics, 28:351-366.

Orlitzky, M., Schmidt, F. L., and Rynes, S. L. (2003). Corporate social and financial performance: A meta-analysis. Organization Studies, 24:403-441.

Social Investment Forum (2006). 2005 Report on Socially Responsible Investing Trends in the United States: 10-Year Review. Social Investment Forum Foundation, Washington, DC.

Turnovsky, S. J. (1990). The effects of taxes and dividend policy on capital accumulation and macroeconomic behavior. Journal of Economic Dynamics and Control, 14:491-521. 


\section{CESifo Working Paper Series}

for full list see www.cesifo-group.org/wp

(address: Poschingerstr. 5, 81679 Munich, Germany, office@cesifo.de)

2285 Axel Dreher and Stefan Voigt, Does Membership in International Organizations Increase Governments' Credibility? Testing the Effects of Delegating Powers, April 2008

2286 Xavier Freixas and Bruno M. Parigi, Lender of Last Resort and Bank Closure Policy, April 2008

2287 Regina Dionisius, Samuel Muehlemann, Harald Pfeifer, Günter Walden, Felix Wenzelmann and Stefan C. Wolter, Cost and Benefit of Apprenticeship Training - A Comparison of Germany and Switzerland, April 2008

2288 Francesco Daveri and Cecilia Jona-Lasinio, Off-Shoring and Productivity Growth in the Italian Manufacturing Industries, April 2008

2289 Mikael Priks, Do Surveillance Cameras Affect Unruly Behavior? A Close Look at Grandstands, April 2008

2290 Marianna Belloc and Daniela Federici, A Two-Country NATREX Model for the Euro/Dollar, April 2008

2291 Nicolas Treich, The Value of a Statistical Life under Ambiguity Aversion, April 2008

2292 J. Atsu Amegashie, Socially-Tolerable Discrimination, April 2008

2293 M. Hashem Pesaran and Andreas Pick, Forecasting Random Walks Under Drift Instability, April 2008

2294 Steven Brakman, Gus Garita, Harry Garretsen and Charles van Marrewijk, Unlocking the Value of Cross-Border Mergers and Acquisitions, May 2008

2295 Eric O’N. Fisher and Kathryn G. Marshall, The Structure of the American Economy, May 2008

2296 Claudia M. Buch and Martin Schlotter, Regional Origins of Employment Volatility: Evidence from German States, May 2008

2297 Helmuth Cremer, Philippe De Donder, Dario Maldonado and Pierre Pestieau, Taxing Sin Goods and Subsidizing Health Care, May 2008

2298 Reinhilde Veugelers and Frederick van der Ploeg, Reforming European Universities: Scope for an Evidence-Based Process, May 2008

2299 Jon H. Fiva and Lars J. Kirkebøen, Does the Housing Market React to New Information on School Quality?, May 2008 
2300 Tina Klautke and Alfons J. Weichenrieder, Interest Income Tax Evasion, the EU Savings Directive, and Capital Market Effects, May 2008

2301 Harald Badinger and Peter Egger, GM Estimation of Higher Order Spatial Autoregressive Processes in Panel Data Error Component Models, May 2008

2302 Jan K. Brueckner, Slot-Based Approaches to Airport Congestion Management, May 2008

2303 Sören Blomquist, Vidar Christiansen and Luca Micheletto, Public Provision of Private Goods and Nondistortionary Marginal Tax Rates, May 2008

2304 Dan Anderberg and Alessandro Balestrino, The Political Economy of Post-Compulsory Education Policy with Endogenous Credit Constraints, May 2008

2305 Tomer Blumkin, Yoram Margalioth and Efraim Sadka, The Role of Stigma in the Design of Welfare Programs, May 2008

2306 Vesa Kanniainen and Paolo M. Panteghini, Tax Neutrality: Illusion or Reality? The Case of Entrepreneurship, May 2008

2307 Thomas Dohmen, Armin Falk, David Huffman and Uwe Sunde, The Intergenerational Transmission of Risk and Trust Attitudes, May 2008

2308 Guglielmo Maria Caporale and Mario Cerrato, Using Chebyshev Polynomials to Approximate Partial Differential Equations, May 2008

2309 Peter Egger and Doina Maria Radulescu, Labour Taxation and Foreign Direct Investment, May 2008

2310 Laurent Linnemer, Dissipative Advertising Signals Quality even without Repeat Purchases, May 2008

2311 Jordi Jofre-Monseny and Albert Solé-Ollé, Which Communities should be afraid of Mobility? The Effects of Agglomeration Economies on the Sensitivity of Firm Location to Local Taxes, May 2008

2312 Andreas Haufler and Ferdinand Mittermaier, Unionisation Triggers Tax Incentives to Attract Foreign Direct Investment, May 2008

2313 Ronel Elul and Piero Gottardi, Bankruptcy: Is it enough to Forgive or must we also Forget?, May 2008

2314 Andreas Irmen and Johanna Kuehnel, Productive Government Expenditure and Economic Growth, May 2008

2315 Beate Henschel, Carsten Pohl and Marcel Thum, Demographic Change and Regional Labour Markets: The Case of Eastern Germany, May 2008 
2316 Gabriel Felbermayr, Wido Geis and Wilhelm Kohler, Restrictive Immigration Policy in Germany: Pains and Gains Foregone?, May 2008

2317 Michael Hofmann, Gerhard Kempkes and Helmut Seitz, Demographic Change and Public Sector Budgets in a Federal System, May 2008

2318 Paul De Grauwe, Macroeconomic Modeling when Agents are Imperfectly Informed, June 2008

2319 Johann K. Brunner and Susanne Pech, Optimum Taxation of Inheritances, June 2008

2320 Thomas Eichner and Marco Runkel, Corporate Income Taxation of Multinationals in a General Equilibrium Model, June 2008

2321 Rainald Borck and Matthias Wrede, Subsidies for Intracity and Intercity Commuting, June 2008

2322 Patricia Apps and Ray Rees, Testing the Pareto Efficiency of Household Resource Allocations, June 2008

2323 Amihai Glazer, Vesa Kanniainen and Panu Poutvaara, Firms' Ethics, Consumer Boycotts, and Signalling, June 2008

2324 Claudia M. Buch, Jörg Döpke and Kerstin Stahn, Great Moderation at the Firm Level? Unconditional vs. Conditional Output Volatility, June 2008

2325 Helmuth Cremer, Philippe De Donder, Dario Maldonado and Pierre Pestieau, Forced Saving, Redistribution and Nonlinear Social Security Schemes, June 2008

2326 M. Hashem Pesaran and Paolo Zaffaroni, Optimal Asset Allocation with Factor Models for Large Portfolios, June 2008

2327 Harald Badinger and Peter Egger, Horizontal versus Vertical Interdependence in Multinational Activity, June 2008

2328 Jan K. Brueckner and Harris Selod, A Theory of Urban Squatting and Land-Tenure Formalization in Developing Countries, June 2008

2329 Paolo M. Panteghini, Corporate Debt, Hybrid Securities and the Effective Tax Rate, June 2008

2330 Guglielmo Maria Caporale, Juncal Cuñado and Luis A. Gil-Alana, Modelling Long-Run Trends and Cycles in Financial Time Series Data, June 2008

2331 Avi Ben-Bassat and Momi Dahan, Social Identity and Voter Turnout, June 2008

2332 Martin R. West and Ludger Wößmann, "Every Catholic Child in a Catholic School”: Historical Resistance to State Schooling, Contemporary Private Competition, and Student Achievement across Countries, June 2008 
2333 Erkki Koskela and Panu Poutvaara, Outsourcing and Labor Taxation in Dual Labor Markets, June 2008

2334 Philippe Choné and Laurent Linnemer, Optimal Litigation Strategies with Signaling and Screening, June 2008

2335 Albert Solé-Ollé and Pilar Sorribas-Navarro, Does Partisan Alignment Affect the Electoral Reward of Intergovernmental Transfers?, June 2008

2336 Antonio Cabrales and Piero Gottardi, Markets for Information: Of Inefficient Firewalls and Efficient Monopolies, June 2008

2337 Sumon Majumdar and Sharun W. Mukand, The Leader as Catalyst - on Leadership and the Mechanics of Institutional Change, June 2008

2338 Ulrich Hange, Tax Competition, Elastic Labor Supply, and Growth, June 2008

2339 Guy Laroque and Bernard Salanié, Does Fertility Respond to Financial Incentives?, June 2008

2340 Adriano Paggiaro, Enrico Rettore and Ugo Trivellato, The Effect of Extending the Duration of Eligibility in an Italian Labour Market Programme for Dismissed Workers, June 2008

2341 Helmut Seitz, Minimum Standards, Fixed Costs and Taxing Autonomy of Subnational Governments, June 2008

2342 Robert S. Chirinko, Leo de Haan and Elmer Sterken, Asset Price Shocks, Real Expenditures, and Financial Structure: A Multi-Country Analysis, July 2008

2343 Wolfgang Leininger, Evolutionarily Stable Preferences in Contests, July 2008

2344 Hartmut Egger and Udo Kreickemeier, Fairness, Trade, and Inequality, July 2008

2345 Ngo Van Long and Bodhisattva Sengupta, Yardstick Competition, Corruption, and Electoral Incentives, July 2008

2346 Florian Baumann, Employment Protection: The Case of Limited Enforceability, July 2008

2347 Alessandro Balestrino, Cinzia Ciardi and Claudio Mammini, On the Causes and Consequences of Divorce, July 2008

2348 Dirk Schindler and Benjamin Weigert, Insuring Educational Risk: Opportunities versus Income, July 2008

2349 Lammertjan Dam and Ben J. Heijdra, The Environmental and Macroeconomic Effects of Socially Responsible Investment, July 2008 